\title{
Genome-wide expression profiling in muscle and subcutaneous fat of lambs in response to the intake of concentrate supplemented with vitamin $\mathrm{E}$
}

Laura González-Calvo ${ }^{1}$, Elda Dervishi ${ }^{2}$, Margalida Joy ${ }^{1}$, Pilar Sarto ${ }^{1}$, Roberto Martin-Hernandez ${ }^{3}$, Magdalena Serrano ${ }^{4}$, Jose M. Ordovás ${ }^{5}$ and Jorge H. Calvo ${ }^{1,6^{*}}$

\begin{abstract}
Background: The objective of this study was to acquire a broader, more comprehensive picture of the transcriptional changes in the L. Thoracis muscle (LT) and subcutaneous fat (SF) of lambs supplemented with vitamin E. Furthermore, we aimed to identify novel genes involved in the metabolism of vitamin $\mathrm{E}$ that might also be involved in meat quality. In the first treatment, seven lambs were fed a basal concentrate from weaning to slaughter (CON). In the second treatment, seven lambs received basal concentrate from weaning to $4.71 \pm 2$. 62 days and thereafter concentrate supplemented with $500 \mathrm{mg}$ dl-a-tocopheryl acetate/kg (VE) during the last 33. $28 \pm 1.07$ days before slaughter.

Results: The addition of vitamin E to the diet increased the a-tocopherol muscle content and drastically diminished the lipid oxidation of meat. Gene expression profiles for treatments VE and CON were clearly separated from each other in the LT and SF. Vitamin E supplementation had a dramatic effect on subcutaneous fat gene expression, showing general up-regulation of significant genes, compared to CON treatment. In LT, vitamin E supplementation caused down-regulation of genes related to intracellular signaling cascade. Functional analysis of SF showed that vitamin E supplementation caused up-regulation of the lipid biosynthesis process, cholesterol, and sterol and steroid biosynthesis, and it down-regulated genes related to the stress response.

Conclusions: Different gene expression patterns were found between the SF and LT, suggesting tissue specific responses to vitamin $\mathrm{E}$ supplementation. Our study enabled us to identify novel genes and metabolic pathways related to vitamin $E$ metabolism that might be implicated in meat quality. Further exploration of these genes and vitamin $E$ could lead to a better understanding of how vitamin $E$ affects the oxidative process that occurs in manufactured meat products.
\end{abstract}

Keywords: Vitamin E, Genome-wide expression profiling, Microarray, Sheep, Musclem, Subcutaneous fat, Meat quality

\footnotetext{
* Correspondence: jhcalvo@aragon.es

'Unidad de Tecnología en Producción Animal, CITA, 59059 Zaragoza, Spain

${ }^{6}$ ARAID, 50004 Zaragoza, Spain

Full list of author information is available at the end of the article
} 


\section{Background}

Vitamin E is a lipid-soluble essential component of human and animal diets due to its powerful antioxidant activity. There are eight different isoforms of vitamin E, and the most active isoform for cell protection appears to be $\alpha$-tocopherol [1]. Alpha-tocopherol is a cell signaling molecule involved in a broad range of effects on cellular systems [2] and specific regulation of gene expression [2-6]; therefore, $\alpha$-tocopherol can influence a number of biological functions by regulating cell signaling at both the mRNA and microRNA (miRNA) levels [7]. So far, the impact and beneficial effects of vitamin $E$ in the prevention of chronic diseases have been mainly associated with its antioxidant properties [8].

Vitamin E is extensively used in animal diets as an antioxidant supplement. Feeding strategy is an important tool to manipulate intramuscular $\alpha$-tocopherol content in animals. An increase in $\alpha$-tocopherol intake can be achieved through grazing systems [9] or by feeding animals with concentrate supplemented with $\alpha$-tocopherol, which can be used as an effective method to reduce the oxidative processes reported in meat products $[10,11]$.

During oxidative processes, the muscle haeminic pigment changes from red oxymyoglobin to brown metmyoglobin, giving the meat an undesirable brownish color [9]. Moreover, lipid oxidation results in the production of free radicals, which are linked to the formation of off-flavors and odors, a reduction in polyunsaturated fatty acids and the production of undesirable compounds, such as potentially toxic peroxides and aldehydes [12]. All of these modifications cause decreases in the freshness and quality of meat and lower consumer acceptance, resulting in considerable economic loss for the meat industry.

So far, efforts to discover the genes and metabolic pathways involved in vitamin $\mathrm{E}$ metabolism have mainly focused on rodents. These studies have reported important long-term effects of vitamin E deficiency on liver gene expression, up-regulation of genes involved in cholesterol synthesis and steroidogenesis, lipid uptake, and anti-oxidative mechanisms $[3,13]$. In addition, vitamin $\mathrm{E}$ in the rat brain affected genes associated with hormones, nerve growth, apoptosis, dopaminergic neurotransmission, and clearance of amyloid- $\alpha$ [14]. Furthermore, genes encoding for muscle structure and extra cellular matrix and those involved in anti-oxidative and anti-inflammatory processes were up-regulated in rat skeletal muscle in response to vitamin E deficiency [15].

Although nutritional science has embraced the tools of genomics, including cDNA arrays in rodent models, few attempts at large-scale or global evaluation of nutritional gene regulation have mainly used rodents as a model. Only a small number of genes are currently known to be related to vitamin $\mathrm{E}$ metabolism in muscle or fat. In the last few years, several studies have explored the transcriptomic adaptations of skeletal muscle in response to different nutrition variables in ruminants [16-19]. Data from these studies have allowed scientists to identify the biochemical mechanisms that could be associated with key physiological processes in animals and to define specific markers for evaluating meat quality.

A better understanding of the genes and metabolic pathways associated with vitamin E metabolism is critical for identifying the key physiological processes associated with vitamin E content, oxidative stress and other metabolic pathways associated with meat quality. The main effect of vitamin $\mathrm{E}$ on meat is to change the lipid oxidation and thus to increase shelf-life of meat. Because lipid oxidation depends mainly on enzyme activity, posttranscriptional and post-translational changes are processes implicated in the shelf-life of meat. However, the identification of genes related to vitamin $\mathrm{E}$ content would be a good starting point for candidate gene selection and single nucleotide polymorphism (SNP) association studies with variations in vitamin $\mathrm{E}$ content and therefore implicated in meat quality. Furthermore, nonantioxidant roles of vitamin E, serving as a regulator of gene/protein, have been described. In this sense, transcriptomic analysis of skeletal muscle could identify metabolic pathways modified by vitamin $\mathrm{E}$ that could influence meat traits.

Therefore, the main objective of this study was to investigate transcriptional changes in the $L$. Thoracis muscle (LT) and subcutaneous fat (SF) of lambs supplemented with vitamin E using the Affymetrix Ovine Gene 1.1 ST whole-genome array. Furthermore, we aimed to identify novel genes that could play important roles in the metabolism of vitamin $\mathrm{E}$ and that might be associated with meat quality traits.

\section{Results}

Alpha-tocopherol muscle content, intramuscular fat, TBARS and metmyoglobin formation

Significant differences in weaning weight and slaughter age (SA), and average daily gain (ADG), from birth to weaning and from birth to slaughter, were found between treatments (Table 1). Animals from the CON group were younger at slaughter $(P<0.05)$. In addition, these animals had greater ADG from birth to weaning $(P<0.01)$ and from birth to slaughter $(P<0.05)$. During the experimental period, the ADG from weaning to slaughter was not significant between treatments. Average daily gain from birth to slaughter and SA were highly correlated between them $\left(r^{2}=-0.90 ; P<0.01\right)$. The results of $\alpha$-tocopherol content, intramuscular fat (IMF) content, thiobarbituric acid-reactive substances (TBARS) and metmyoglobin (MMb) formation in the LT muscle for each treatment are shown in Table 1. Our results showed that the content of $\alpha$-tocopherol in the 
Table 1 Effect of the dietary treatment on slaughter age and weight, growth rate, alpha-tocopherol muscle content, intramuscular fat, TBARS and metmyoglobin formation

\begin{tabular}{|c|c|c|c|c|}
\hline \multicolumn{5}{|l|}{ Treatment $^{1}$} \\
\hline & CON & VE & SE & $P$-value \\
\hline \multicolumn{5}{|l|}{ Performance } \\
\hline Weaning Weight (kg) & 15.29 & 11.59 & 0.5246 & $* *$ \\
\hline Slaughter Age (days) & 72.28 & 86.28 & 3.59 & * \\
\hline Slaughter Weight (kg) & 23.20 & 22.71 & 0.45 & ns \\
\hline \multicolumn{5}{|l|}{ Average Daily Gain (g/day) } \\
\hline - From birth to weaning & 281.43 & 203.71 & 11.10 & $* *$ \\
\hline - Experimental period ${ }^{2}$ & 337.86 & 276.57 & 22.70 & ns \\
\hline - From birth to slaughter & 278.14 & 230.57 & 12.25 & * \\
\hline \multicolumn{5}{|l|}{ L. Thoracis muscle } \\
\hline a-Tocopherol, mg/kg muscle & 0.13 & 2.26 & 0.07 & $* * *$ \\
\hline IMF (\% fresh matter) & 2.03 & 1.68 & 0.25 & ns \\
\hline $\operatorname{TBARS}(7 \mathrm{~d})^{3}$ & 1.62 & 0.07 & 0.17 & $* * *$ \\
\hline$K / S_{572 / 525}(7 d)^{4}$ & 0.93 & 1.06 & 0.03 & * \\
\hline
\end{tabular}

'CON: commercial concentrate without VE supplement; VE: VE concentrate for $33.3 \pm 1.07$ days before slaughter. Means within a row with different superscripts differ $(P<0.05)$; SE: standard error; ns: not significant; ${ }^{* * *} P<0.001$; ${ }^{*} P<0.01 ; * P<0.05$; ${ }^{2}$ Experimental period started at $48 \mathrm{~d}$ old. ${ }^{3}$ TBARS: $\mathrm{mg}$ of malonaldehyde per $\mathrm{kg}$ of $\mathrm{L}$. Thoracis muscle at 7 days of display; ${ }^{4} \mathrm{~K} / \mathrm{S}_{572 / 525}$ : ratio of metmyoglobin formation of $\mathrm{L}$. Thoracis muscle at 7 days of display

muscle was significantly higher in lambs that received a basal concentrate supplemented with $\mathrm{dl}-\alpha$-tocopheryl acetate (VE), while lambs fed a basal concentrate (CON) showed higher values of TBARS ( $\mathrm{mg}$ of malonaldehyde per $\mathrm{kg}$ of $\mathrm{L}$. Thoracis) $(P<0.05)$. Furthermore, metmyoglobin formation was significantly lower in VE lambs, compared to the CON group $(P<0.05)$. The $\mathrm{K} / \mathrm{S}_{572 / 525}$ ratio decreased when the metmyoglobin content increased. Intramuscular fat (IMF) content was not different between the treatments $(P>0.05)$.

\section{Microarray gene expression results Identification and classification of differentially expressed genes by microarray analysis in LT and SF}

Significance analysis of microarray (SAM) was performed to compare the VE treatment with CON. SAM identified a total of 29 genes with a false discovery rate $($ FDR $)=$ $0.008,26$ down- regulated and 3 up-regulated genes (Table 2). The results of SAM regarding LT muscle are shown in Fig. 1.

Regarding subcutaneous fat, when VE treatment was compared with the CON group, SAM identified a total of 330 genes with a FDR $<0.001$. Among these genes, 295 were up-regulated, and 35 were down-regulated. The results of the top 50 genes identified with SAM for SF are shown in Table 3. In Additional file 1: Table S1 all of the significant genes in SF are ranked according to their fold change (FC). Notably, H1FO gene was found to be significantly down-regulated in VE lambs in both tissues.

\section{Treatment-dependent multivariate analysis results of gene expression}

In the LT muscle, principal component analysis (PCA) of the complete set of 32 genes identified by SAM showed that the first 2 PCs covered $39.7 \%$ of the observed variance in the sample set (Fig. 2a). The PCA score plot revealed differences corresponding to lambs fed with the two different treatments. The ellipse corresponding to CON was clearly separated from the VE treatment. Partial least squares-discriminate analysis (PLS-DA) showed a clear separation of the two groups (Fig. 2b). In addition, PLS-DA allowed for the identification of the genes that were most important for the separation observed in the score plots. $D E F 8$ gene showed the highest score, followed by ASPN and AKR7A2 (Fig. 2c). Moreover, we investigated trends or patterns in gene expression changes (Fig. 2d). For example, $A B C C 4$, $D E P T O R, I G F R 1, M Y L K 2$ and $A C A T 1$ were positively correlated with each other in the two treatments, showing a down- and up-regulation in the VE and CON treatments, respectively. In contrast, they were negatively correlated with SAT1, ASPN, or LRRTM2. These genes, which are either positively or negatively correlated with each other, appeared to play an important role in light of the PCA and PLS-DA cluster analysis.

Multivariate analysis results from subcutaneous fat were used to cluster the samples based on gene expression profiles of animals fed two different diets: CON and VE. The PCA of the complete set of 330 genes identified by SAM showed that the first 2 PCs covered $68 \%$ of the observed variance of the sample set (Fig. 3a). The figure shows the score plot of the two first principal components extracted in this study. PLS-DA showed that the $\mathrm{VE}$ and CON groups were clearly separate from each other. (Fig. 3b). In addition, PLS-DA allowed for the identification of the most important genes contributing to the separation observed in the score plots, and $A L G 11$ had the highest score, followed by SRPBR and PPX47.

Moreover, we investigated patterns in gene expression changes in subcutaneous fat (Fig. 3d). For example, the gene expressions of $A L G 11, S R P B R$, and PPX47 were positively correlated with each other, being up-regulated in VE treatment.

\section{Hierarchical clustering analysis (HCA)}

HCA was performed using the significant genes obtained by SAM for both contrasts. The results of HCA for LT muscle are presented in Fig. 4a. The expression profile of these genes was able to cluster and to classify correctly the samples within their corresponding groups. 
Table 2 The significant features identified by SAM in VE vs. CON contrast in L. Thoracis muscle

\begin{tabular}{|c|c|c|c|}
\hline $\begin{array}{l}\text { Gene } \\
\text { symbol }\end{array}$ & Gene name & $q$ value & FC \\
\hline AKRTA2 & aldo-keto reductase family 7, member $\mathrm{A} 2$ & 0 & -1.25 \\
\hline DEF8 & $\begin{array}{l}\text { differentially expressed in FDCP } 8 \\
\text { homolog }\end{array}$ & 0 & -1.20 \\
\hline ASPN & asporin & 0 & 1.65 \\
\hline PPP6R3 & $\begin{array}{l}\text { Protein Phosphatase 6, Regulatory } \\
\text { Subunit } 3\end{array}$ & 0.00295 & -1.14 \\
\hline SAT1 & $\begin{array}{l}\text { spermidine/spermine N1-acetyltransferase } \\
1\end{array}$ & 0.00295 & 1.55 \\
\hline KLHL33 & kelch-like 33 & 0.00442 & -1.30 \\
\hline$A B C C 4$ & $\begin{array}{l}\text { ATP-binding cassette, sub-family C (CFTR/ } \\
\text { MRP), member } 4\end{array}$ & 0.00925 & -1.22 \\
\hline $\mathrm{CISH}$ & $\begin{array}{l}\text { cytokine inducible SH2-containing } \\
\text { protein }\end{array}$ & 0.00954 & -2.05 \\
\hline AKAP7 & A kinase (PRKA) anchor protein 7 & 0.00954 & -1.53 \\
\hline$A C A C B$ & acetyl-Coenzyme A carboxylase beta & 0.00954 & -1.41 \\
\hline$M A F B$ & $\begin{array}{l}\text { v-maf musculoaponeurotic fibrosarcoma } \\
\text { oncogene homolog B }\end{array}$ & 0.00954 & -1.37 \\
\hline HiFO & $\mathrm{H} 1$ histone family, member 0 & 0.00954 & -1.32 \\
\hline MYLK2 & myosin light chain kinase 2 & 0.00954 & -1.31 \\
\hline DUSP26 & dual specificity phosphatase 26 (putative) & 0.00954 & -1.30 \\
\hline RSCIA1 & $\begin{array}{l}\text { regulatory solute carrier protein, family } 1 \text {, } \\
\text { member } 1\end{array}$ & 0.00954 & -1.28 \\
\hline FHL3 & four and a half LIM domains 3 & 0.00954 & -1.26 \\
\hline ACAT1 & acetyl-Coenzyme A acetyltransferase 1 & 0.00954 & -1.25 \\
\hline FAM151A & $\begin{array}{l}\text { family with sequence similarity } 151, \\
\text { member A }\end{array}$ & 0.00954 & -1.23 \\
\hline KIAA0430 & KIAA0430 & 0.00954 & -1.22 \\
\hline ZNF777 & zinc finger protein 777 & 0.00954 & -1.20 \\
\hline DEPTOR & $\begin{array}{l}\text { DEP Domain Containing MTOR- } \\
\text { Interacting Protein }\end{array}$ & 0.00954 & -1.19 \\
\hline LRRTM2 & $\begin{array}{l}\text { leucine rich repeat transmembrane } \\
\text { neuronal } 2\end{array}$ & 0.00954 & 1.26 \\
\hline DDX39B & $\begin{array}{l}\text { DEAD (Asp-Glu-Ala-Asp) Box Polypeptide } \\
\text { 39B }\end{array}$ & 0.00974 & -1.43 \\
\hline PGLS & 6-phosphogluconolactonase & 0.0097 & -1.21 \\
\hline BTNL9 & butyrophilin-like 9 & 0.01006 & -1.39 \\
\hline$F B X L 4$ & F-box and leucine-rich repeat protein 4 & 0.01006 & -1.38 \\
\hline IGF1R & insulin-like growth factor 1 receptor & 0.01006 & -1.17 \\
\hline ST6GALNAC6 & $\begin{array}{l}\text { ST6-N-acetylgalactosaminide alpha-2,6- } \\
\text { sialyltransferase } 6\end{array}$ & 0.01006 & 1.14 \\
\hline ANAPC16 & chromosome 10 open reading frame 104 & 0.01006 & 1.25 \\
\hline
\end{tabular}

The heatmap shows the presence of 2 different clusters containing different genes. The responses of each variable to the two different treatments are indicated with changes in the color intensity on the heatmap. The VE and $\mathrm{CON}$ groups showed very different gene expression patterns. For instance, LRRTM2, ASPN and SAT1 were up-regulated in the VE group. Furthermore, a second cluster including the remainder of the genes was found to be down-regulated in the VE group. These two clusters distinguished the VE group from the $\mathrm{CON}$ group. These genes are involved in different metabolic processes.

Regarding subcutaneous fat, the results of clustering analysis of top 50 genes are presented in Fig 4b. Analyzing the heatmap, it can be observed that the CON group showed very different gene expression patterns from the VE group. There is a general down-regulation of gene expression in the CON group and an upregulation of gene expression in the VE group. The results of clustering analysis of the total 330 genes in subcutaneous fat were similar to the 50 genes analysis results, but one VE animal was clustered in the CON group (Additional file 2: Figure S1). More specifically, 34 genes were down- regulated in the VE group ( $S O D 3$, CLEC3B, METTL7A, IER3, PLK2, CLEC1A, HSPA1A, TNFSF10, MERTK, MLLT3, TPPP2, HMGB2, PECAM1, IFITM3, H1FO, HMG2OB, GALK1, NFIL3, CDH5, ERG, CEBPA, ANKRD44, HCST, UACA, IFITM1, RPL10, PID1, LUC7L3, H3F3A, AMOTL2, PSIP1, RPL17, TRA2A, and RPS259).

\section{Functional clustering annotation}

In the LT muscle, the results of Database for Annotation, Visualization and Integrated Discovery (DAVID) functional annotation clustering (FAC), including the 29 significant genes in the VE-CON contrast, showed that 4 genes from the "intracellular signaling cascade" (IGF1R, $D E F 8, A K A P 7$ and $C I S H$ ) had the most enrichment and were all down-regulated in the VE treatment (Additional file 3: Table S2). However, the confident enrichment scores were less than 1.3 in both cases.

In subcutaneous fat, the results of DAVID FAC of 330 significant genes in the VE-CON contrast, revealed that the most significantly enriched cluster was "lipid biosynthesis process", (enrichment score of 5.38) with a total of 20 genes involved (PGAP3, EBP, CRLS1, MVD, CYP51A1, GNE, HMGCS1, DPAGT1, LSS, SIGMAR1, LPCAT3, FDFT1, DOLK, PIGM, SQLE, DHCR7, AGPAT9, LTA4H, PCYT2 and HSD17B7), all of them up-regulated in the VE group compared to the CON group. Many of these genes play roles in the cholesterol, sterol and steroid biosynthesis. In Table 4, the DAVID FAC results of the 330 genes in the VE-CON contrast are shown.

\section{Validation of microarrays results using $\mathrm{QPCR}$}

Thirteen genes were selected to validate the microarray results by quantitative real-time PCR (qPCR). The gene set included 4 genes in muscle and 9 genes in subcutaneous fat. In LT muscle, the genes were selected because they were significant differentially expressed between the 
a

SAM Plot for Delta $=1.6$

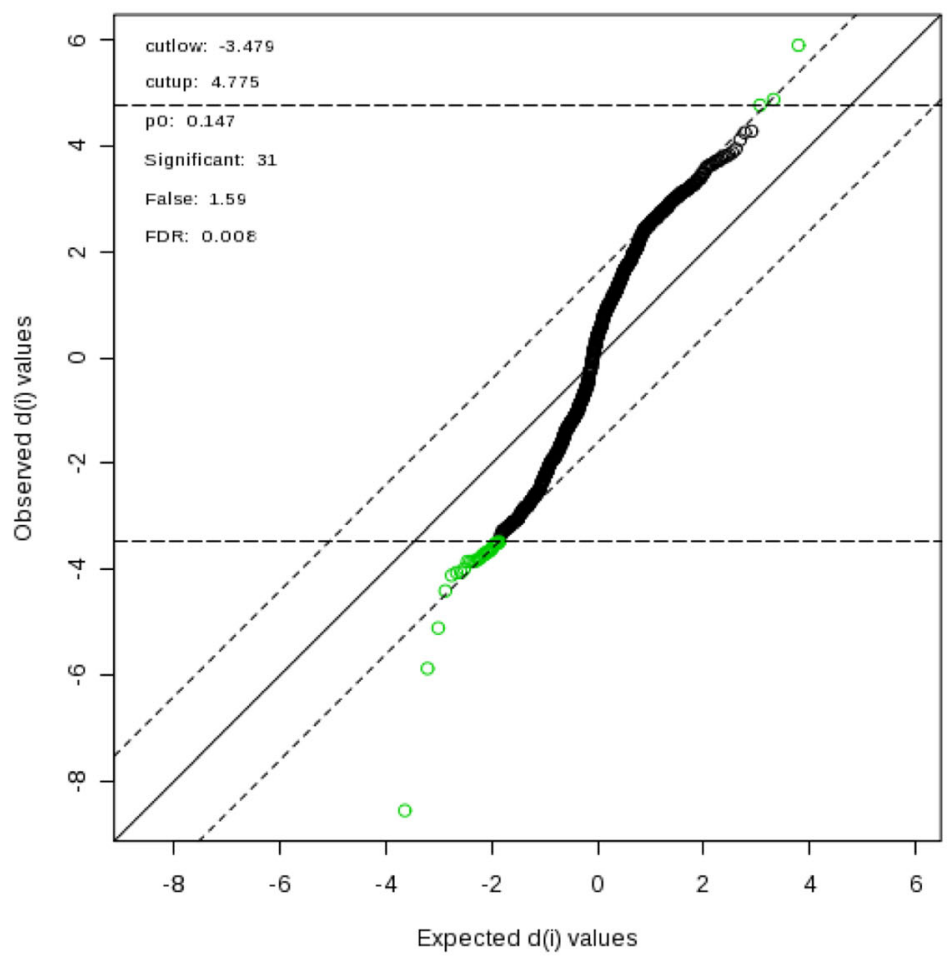

b

SAM Plot for Delta $=2$

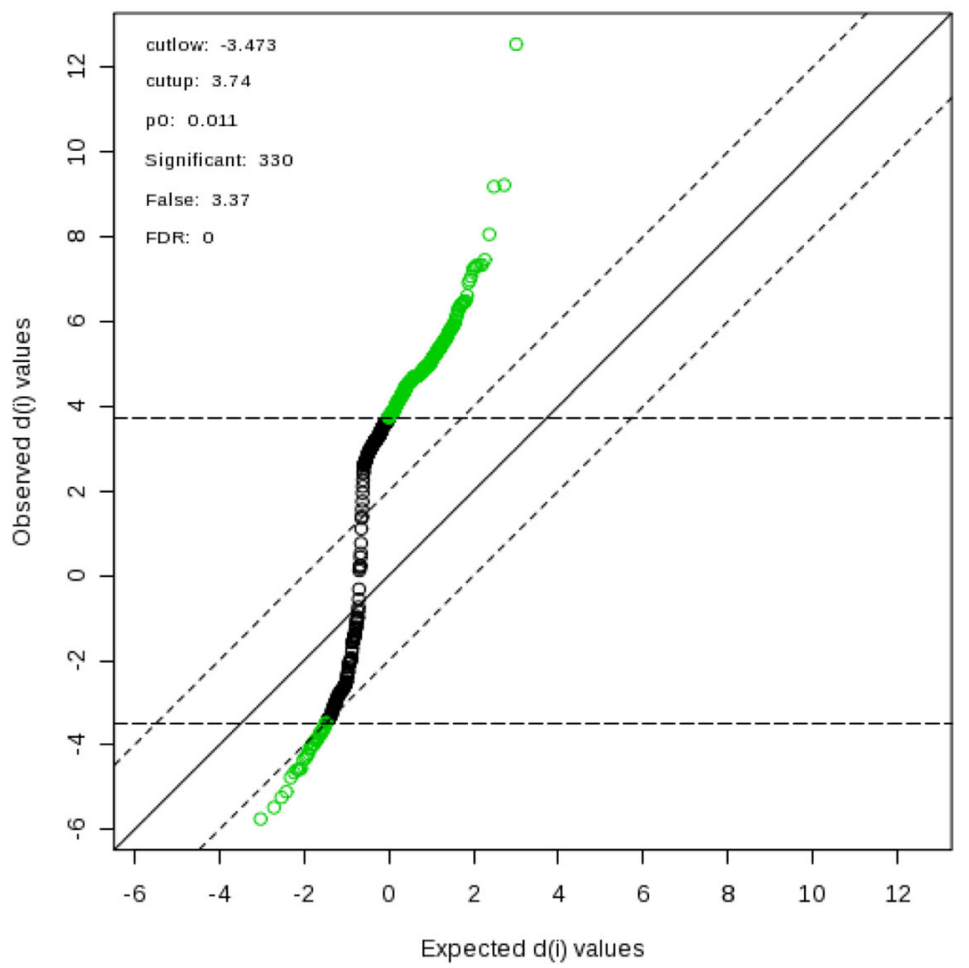

Fig. 1 Significant features identified by SAM in a VE-CON contrast in LT, and $\mathbf{b}$ VE-CON contrast in SF. The green circles represent features that exceed the specified threshold 
Table 3 Top 50 genes identify with SAM in VE vs. CON contrast in subcutaneous fat

\begin{tabular}{|c|c|c|c|c|c|c|c|}
\hline & \\
\hline Gene symbol & Gene Name & $q$ value & $\mathrm{FC}$ & $\overline{C N P Y 4}$ & canopy 4 homolog & $2.81 \mathrm{E}-05$ & 1.48 \\
\hline$\overline{D D X 47}$ & $\begin{array}{l}\text { DEAD (Asp-Glu-Ala-Asp) box } \\
\text { polypeptide } 47\end{array}$ & 0 & 1.50 & KIAA1274 & $\begin{array}{l}\text { Phosphatase Domain Containing, } \\
\text { Paladin } 1\end{array}$ & $2.81 \mathrm{E}-05$ & 1.48 \\
\hline ALG11 & $\begin{array}{l}\text { UTP14, U3 small nucleolar } \\
\text { ribonucleoprotein, homolog C }\end{array}$ & 0 & 1.67 & AKAP10 & A kinase (PRKA) anchor protein 10 & $2.81 \mathrm{E}-05$ & 1.48 \\
\hline$S R P R B$ & $\begin{array}{l}\text { signal recognition particle receptor, } \\
\text { B subunit }\end{array}$ & 0 & 2.30 & HNRNPH2 & $\begin{array}{l}\text { ribosomal protein L36a pseudogene } \\
51\end{array}$ & $2.81 \mathrm{E}-05$ & 1.52 \\
\hline TTC37 & tetratricopeptide repeat domain 37 & 1.07E-05 & 1.32 & MCU & mitochondrial calcium uniporter & 2.81E-05 & 1.53 \\
\hline RRAGA & Ras-related GTP binding A & 1.07E-05 & 1.40 & SLC39A3 & $\begin{array}{l}\text { solute carrier family } 39 \text { (zinc } \\
\text { transporter), member } 3\end{array}$ & $2.81 \mathrm{E}-05$ & 1.57 \\
\hline LRRC59 & leucine rich repeat containing 59 & $1.07 \mathrm{E}-05$ & 1.47 & EMC8 & omplex & $2.81 \mathrm{E}-05$ & 1.59 \\
\hline RASSF8 & Ras association domain family & $1.07 E-05$ & 1.55 & & & & \\
\hline ELP3 & $\begin{array}{l}\text { (N-terminal) member } 8 \\
\text { elongation protein } 3 \text { homolog }\end{array}$ & 1.07E-05 & 1.56 & PROSC & $\begin{array}{l}\text { proline synthetase co-transcribed } \\
\text { homolog }\end{array}$ & $2.81 \mathrm{E}-05$ & 1.62 \\
\hline SEC23IP & SEC23 interacting protein & $1.07 \mathrm{E}-05$ & 1.61 & $A B C F 3$ & ATP-binding cassette, sub-family $F$ & 2.81E-05 & 1.65 \\
\hline TMEM181 & transmembrane protein 181 & 1.07E-05 & 1.65 & ᄃ/127? & & & \\
\hline CAND1 & $\begin{array}{l}\text { cullin-associated and neddylation- } \\
\text { dissociated } 1\end{array}$ & $1.53 \mathrm{E}-05$ & 1.39 & 7220 rt 28 & $\begin{array}{l}\text { chromosome } 5 \text { open reading trame, } \\
\text { human C22orf28 }\end{array}$ & 2.81E-05 & 1.67 \\
\hline PIGM & phosphatidylinositol glycan anchor & 1.53E-05 & 1.42 & PINX1 & PIN2-interacting protein 1 & $2.81 \mathrm{E}-05$ & 1.69 \\
\hline & biosynthesis, class M & & & ADPGK & ADP-dependent glucokinase & 2.81E-05 & 1.75 \\
\hline TMEM203 & transmembrane protein 203 & $1.53 \mathrm{E}-05$ & 1.52 & CERS6 & ceramide synthase 6 & 2.81E-05 & 1.76 \\
\hline$A B C E 1$ & sette, & $1.53 \mathrm{E}-05$ & 1.69 & DOLPP1 & dolichyl pyrophosphate phosphatase 1 & 2.81E-05 & 1.79 \\
\hline & & & & DOLK & dolichol kinase & 2.81E-05 & 1.86 \\
\hline WDR55 & WD repeat domain 55 & 2.01E-05 & 1.31 & RPS4Y1 & ribosomal protein S4, Y-linked 1 & $2.81 \mathrm{E}-05$ & 1.90 \\
\hline SLC35A4 & solute carrier family 35 , member A4 & 2.01E-05 & 1.32 & TIMM8A & translocase of inner mito & 2.81E-05 & 2.27 \\
\hline$A R P C 5$ & actin related protein $2 / 3$ complex, & 2.04E-05 & 1.29 & & & & \\
\hline
\end{tabular}

MINPP subunit 5, $16 \mathrm{kDa}$

2.04E-05 1.38 histidine phosphatase, 1

RER1

TIMM22 translocase of inner mitochondrial

RER1 retention in endoplasmic reticulum 1 homolog membrane 22 homolog

EXTL3 exostoses (multiple)-like 3

GMPS

SLC39A7

guanine monphosphate synthetase

solute carrier family 39 (zinc

transporter), member 7

MARS

RAB22A

methionyl-tRNA synthetase

RAB22A, member RAS oncogene family

\section{ADSS adenylosuccinate synthase}

IER3

RNF121

DNAJC5

immediate early response 3

ring finger protein 121

DnaJ (Hsp40) homolog, subfamily C, member 5

NUDT9

WAPAL

FBXO28

AP1S1 nudix (nucleoside diphosphate $\quad 2.81 \mathrm{E}-05 \quad 1.36$

linked moiety X)-type motif 9

wings apart-like homolog

2.81E-05

$2.81 \mathrm{E}-05$

2.81E-05
Table 3 Top 50 genes identify with SAM in VE vs. CON contrast in subcutaneous fat (Continued)

$\mathrm{VE}$ and CON treatments (CISH, ABCC4, ACAT1 and $I G F 1 R)$. In SF, the significant genes in the VE-CON contrast (LDLR, SOD3, SQLE, SREBF1, MTTL1, HAX1, $H M G B 2, H S P B 8$ and IER3) were selected. Although the magnitude of FC obtained by microarray and $\mathrm{qPCR}$ was slightly different in some instances, the qPCR results demonstrated a similar trend compared with the microarray results of these 13 genes, demonstrating the reliability of microarray analysis (Pearson's correlation coefficient $0.99, P=0.008$ for LT muscle and $0.99, P<0.001$ for SF) (Table 5).

\section{Discussion}

The aim of the present study was to assess the effects of adding VE to the fattening concentrate, fed between weaning and slaughter, on the transcriptional changes in the LT and SF. The experimental period ended when the lambs reached the target slaughter LW (22-24 kg), according to the specifications of Ternasco de Aragón Protected Geographical Indication (Regulation (EC) No. 1107/96). The light lamb production is based on two periods: suckling and fattening. The suckling period is usually limited by the time, usually lasting approximately $45 \mathrm{~d}$ (in the present study, it was $48 \mathrm{~d}$ ), while the 

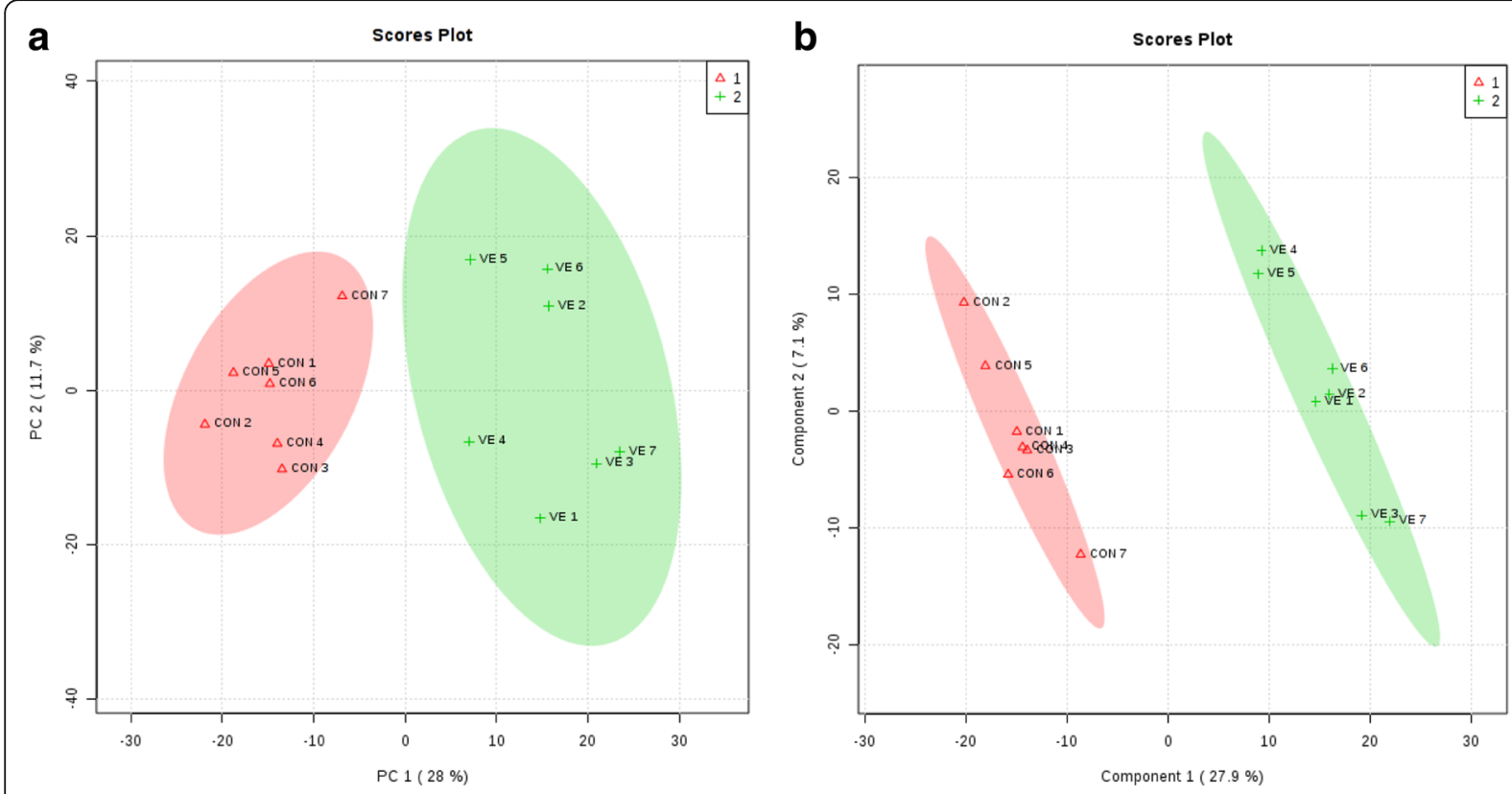

C

Top 25 compounds correlated with the 1-2

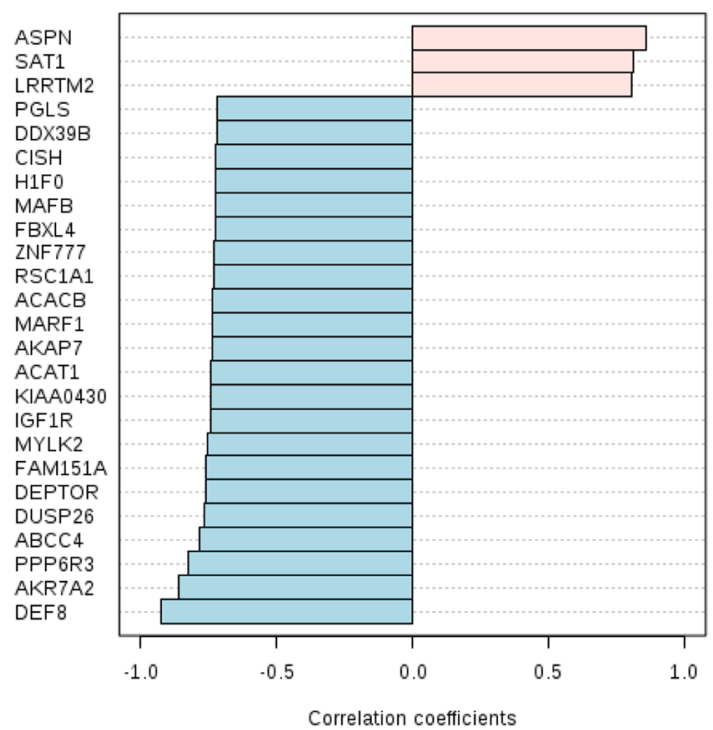

d

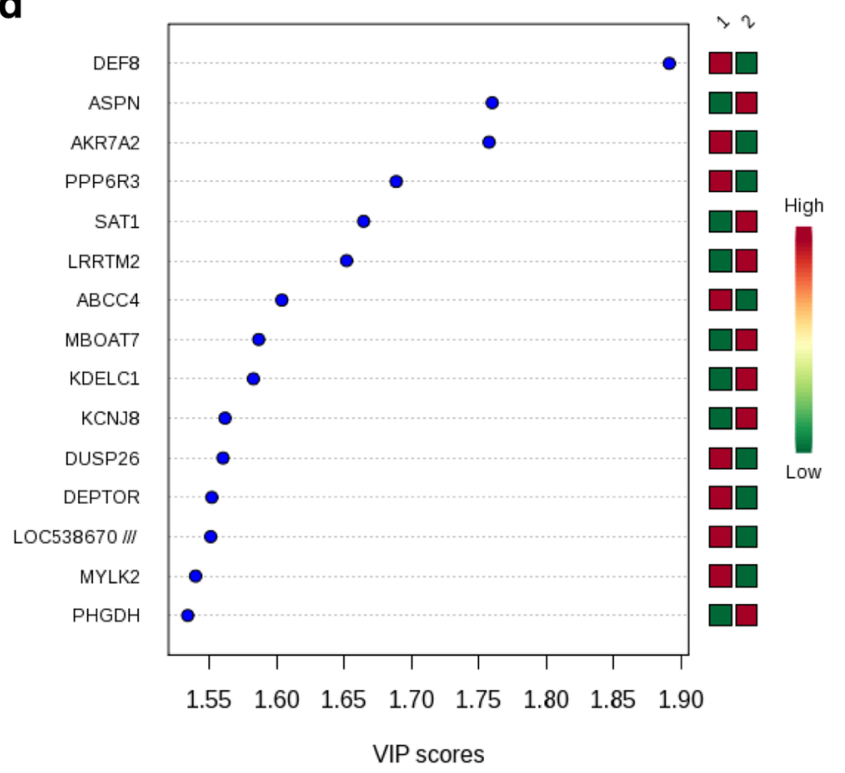

Fig. 2 Multivariate analysis based on gene expression profile data in LT muscle. a Principal component analysis (PCA) score plots distinguishing between the LT muscle of lambs fed concentrate (triangle), and supplemented with vitamin E in the treatment, (+). b Partial least squaresdiscriminant analysis (PLC-DA) based on gene expression profile data. c Important features identified by PLS-DA. The top 15 genes are ranked by VIP scores. The colored boxes on the right indicate the relative expression of the corresponding gene in each group under study. $\mathbf{d}$ A bar graph showing the top 25 genes correlating with diet (CON, VE). Variables with the same distance from 0 with similar positions are positively correlated. Those with the opposite direction are negatively correlated. The light blue bars indicate genes showing a negative correlation, and the light pink bars indicate those with a positive correlation with the given pattern of change of treatment

fattening period is limited by the weight $(22-24 \mathrm{~kg} \mathrm{LW})$. Thus, lambs with high ADG during lactation period spent fewer days in the fattening period than those with low ADG. To be able to evaluate the potential effects of the inclusion of VE on the transcriptome of the $L$. Thoracis muscle and subcutaneous fat, we planned to feed at least 30 days of VE concentrate. According to Ripoll et al. [11], supplementation with VE for 30 days was found to increase noticeably concentration of the $\alpha$-tocopherol content in muscle. In the present study, the ADG during the experimental period was not different, however during the suckling period it was lower in VE treatment $(p<$ 0.01 ; Table 1). This implies that the lambs of the VE treatment during the suckling period presented lower growth 

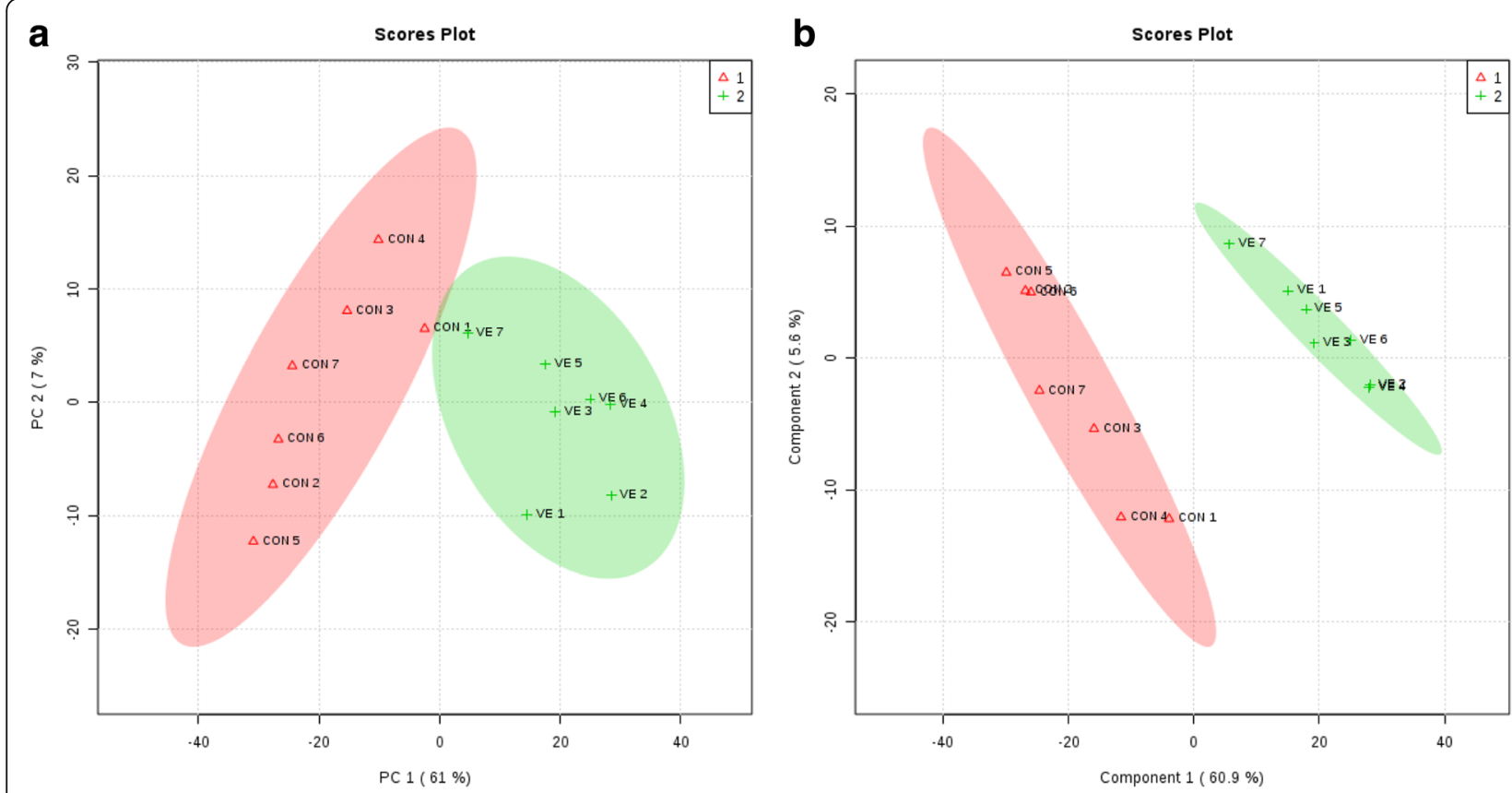

C

Top 25 peaks(mz/rt) correlated with the 1.2

d
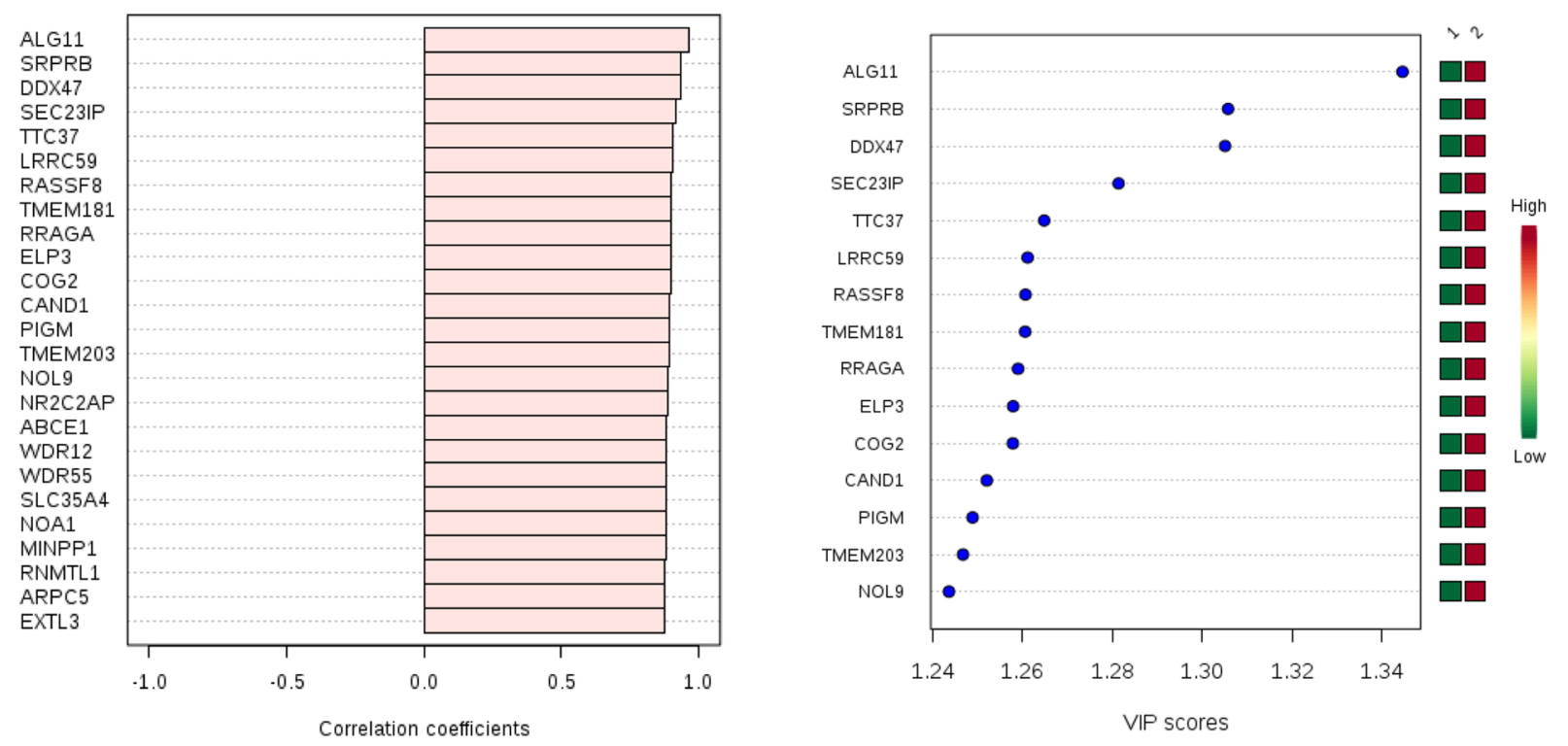

Fig. 3 Multivariate analysis based on gene expression profile data in subcutaneous fat. a Principal component analysis (PCA) score plots distinguishing between the subcutaneous fat of lambs fed concentrate (triangle), and supplemented with vitamin E in the treatment (+). b Partial least squares-discriminant analysis (PLC-DA) based on gene expression profile data. c Important features identified by PLS-DA. The top 15 genes are ranked by VIP scores. The colored boxes on the right indicate the relative expression of the corresponding gene in each group under study. $\mathbf{d}$ A bar graph showing the top 25 genes correlating with treatment (CON, VE). Variables with the same distance from 0 with similar positions are positively correlated. Those with the opposite direction are negatively correlated The light pink bars indicate genes with a positive correlation with the given pattern of change of treatment

compared to the CON group and needed more days to reach the target weight. Moreover, there was a strong correlation between ADG from birth to slaughter and SA $\left(r^{2}\right.$ $=-0.9$ ). Therefore, to overcome this unbalance between treatments ADG values were included as covariates in the statistical model used to validate gene expression differences by qPCR, thus avoiding estimation biases. We analyzed LT muscle and SF because meat cuts for human consumption include both intramuscular and subcutaneous fat [20], constituting the total amount of meat fat 

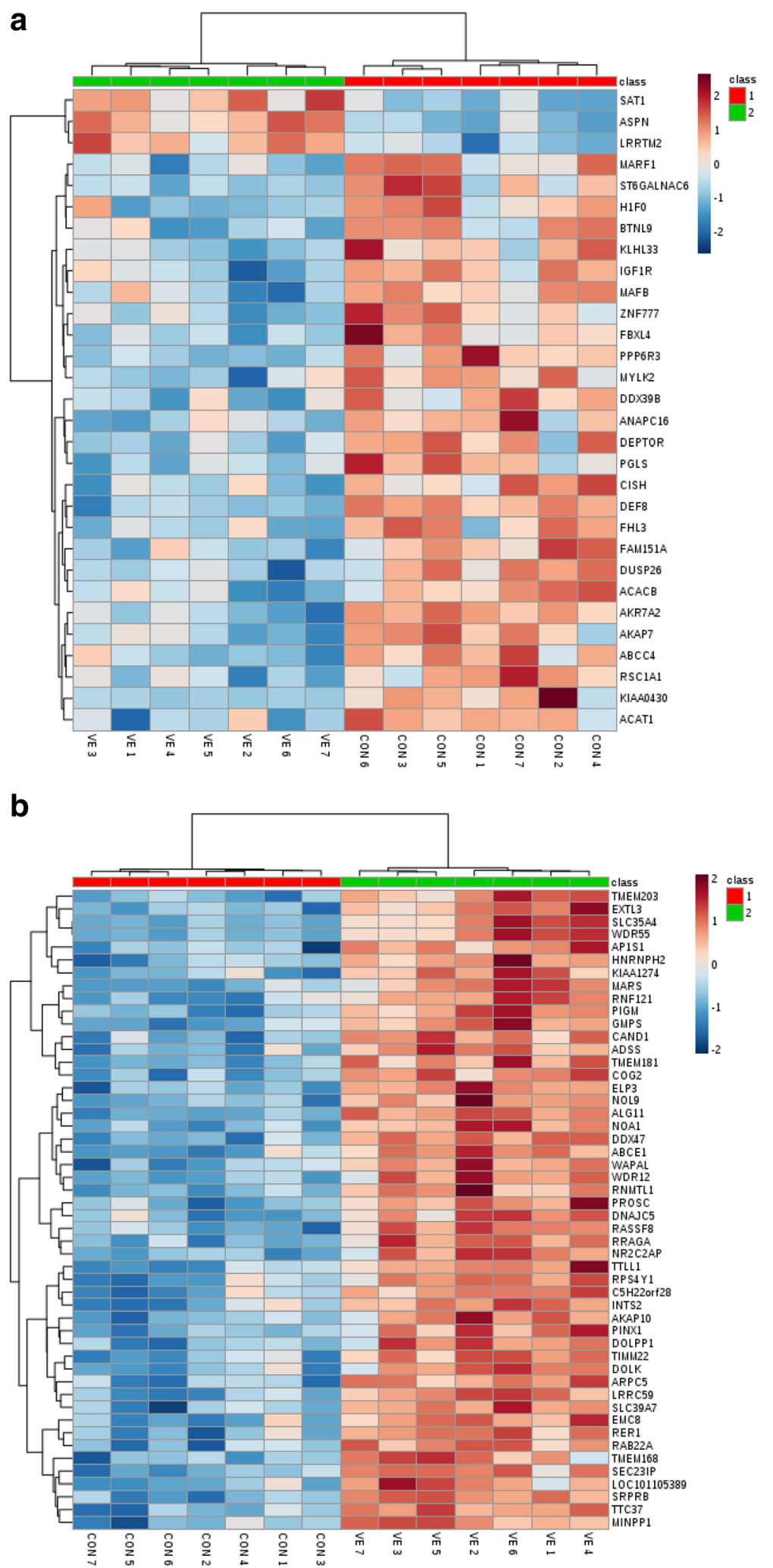

Fig. 4 Hierarchical clustering analysis of gene expression in a) the L. Thoracis muscle, b) subcutaneous fat tissue of lambs receiving different treatments (CON and VE), using the most significant genes of each contrast. Cells are colored based on the signal intensity measured. Dark brown represents high gene expression levels, blue indicates low signal intensity, and gray indicates the intermediate level (see color scale above the heatmap) 
Table 4 DAVID Functional Annotation Clustering of SAM genes in VE vs. CON subcutaneous fat

\begin{tabular}{|c|c|c|c|c|}
\hline \multicolumn{5}{|l|}{ Annotation Cluster 1} \\
\hline \multicolumn{5}{|l|}{ Enrichment Score: 5.82} \\
\hline Category & Term & Count & $\%$ & $P$ Value \\
\hline GOTERM_BP_FAT & GO:0016126 sterol biosynthetic process & 9 & 3.26 & $6.03 \mathrm{E}-08$ \\
\hline GOTERM_BP_FAT & GO:0016125 sterol metabolic process & 12 & 4.35 & $6.02 \mathrm{E}-07$ \\
\hline GOTERM_BP_FAT & GO:0008610 lipid biosynthetic process & 20 & 7.25 & $1.04 \mathrm{E}-06$ \\
\hline GOTERM_BP_FAT & $\begin{array}{l}\text { GO:0008203 cholesterol metabolic } \\
\text { process }\end{array}$ & 11 & 3.99 & $2.01 \mathrm{E}-06$ \\
\hline GOTERM_BP_FAT & $\begin{array}{l}\text { GO:0006695 cholesterol biosynthetic } \\
\text { process }\end{array}$ & 7 & 2.54 & $2.73 \mathrm{E}-06$ \\
\hline GOTERM_BP_FAT & GO:0006694 steroid biosynthetic process & 10 & 3.62 & $8.22 \mathrm{E}-06$ \\
\hline GOTERM_BP_FAT & GO:0008202 steroid metabolic process & 13 & 4.71 & $9.78 \mathrm{E}-05$ \\
\hline
\end{tabular}

Annotation Cluster 2

Enrichment Score: 3.59

GOTERM_BP_FAT GO:0015031 protein transport

GOTERM_BP_FAT GO:0045184 establishment of protein localization

GOTERM_BP_FAT GO:0008104 protein localization

GOTERM_BP_FAT

$0033365 \sim$ protein localization in organelle

GOTERM_BP_FAT

GO:0006626 protein targeting to mitochondrion

GOTERM_BP_FAT

GOTERM_BP_FAT

GOTERM_BP_FAT

GO:0070727 cellular macromolecule localization

Annotation Cluster 3

Enrichment Score: 3.00

$\begin{array}{ll}\text { GOTERM_BP_FAT } & \begin{array}{l}\text { GO:0008299 isoprenoid biosynthetic } \\ \text { process }\end{array} \\ \text { GOTERM_BP_FAT } & \begin{array}{l}\text { GO:0006720 isoprenoid metabolic } \\ \text { process }\end{array}\end{array}$

GO:0070585 protein localization in mitochondrion

GO:0034613 cellular protein localization
29

$10.51 \quad 3.19 \mathrm{E}-05$

4.71 2.11E-06

NDUFAF4, CAV2, DNM1L, MTX2, TOMM40, TIMM44, TIMM8A, TRNT1, GFM2, MRPL12, FXC1, PTCD2,

DNAJA3

SNX19, MTX2, SNX4, RAB1A, COPB2, AP1S1, FXC1, VPS4A, NUP35, SEC23IP, ZW10, RAB2B, SRP54, VPS45, TOMM40, NUP85, AP4S1, TIMM44, TIMM8A, TIMM22, TRNT1, YWHAG, PLEKHA8, RAB22A, KPNA6, NOP58, NUP43, KPNA1, SNX11

SNX19, MTX2, SNX4, RAB1A, COPB2, AP1S1, FXC1, VPS4A, NUP35, SEC23IP, ZW10, RAB2B, SRP54, VPS45, TOMM40, NUP85, AP4S1, TIMM44, TIMM8A, TIMM22, TRNT1, YWHAG, PLEKHA8, RAB22A, KPNA6, NOP58, NUP43, KPNA1, SNX11

SNX19, MTX2, SNX4, AKAP10, RAB1A, COPB2, AP1S1, FXC1, PIKFYVE, VPS4A, NUP35, SEC23IP, ZW10, RAB2B, SRP54, VPS45, TOMM40, NUP85, AP4S1, TIMM44, TIMM8A, TIMM22, TRNT1, YWHAG, PLEKHA8, RAB22A, KPNA6, NOP58, NUP43, KPNA1, SNX11

TRNT1, SRP54, MTX2, FXC1, PIKFYVE, KPNA6, TOMM40, NOP58, TIMM44, KPNA1, TIMM8A

TRNT1, MTX2, FXC1, TOMM40, TIMM44, TIMM8A

$\begin{array}{lll}6 & 2.17 \quad 1.89 \mathrm{E}-04\end{array}$

$6 \quad 2.17 \quad 1.89 \mathrm{E}-04$

TRNT1, MTX2, FXC1, TOMM40, TIMM44, TIMM8A

SRP54, VPS45, MTX2, TOMM40, AP4S1, TIMM44, TIMM8A, TRNT1, COPB2, YWHAG, AP1S1, FXC1, PIKFYVE, KPNA6, NOP58, SEC23IP, KPNA1, ZW10

SRP54, VPS45, MTX2, TOMM40, AP4S1, TIMM44, TIMM8A, TRNT1, COPB2, YWHAG, AP1S1, FXC1, PIKFYVE, KPNA6, NOP58, SEC23IP, KPNA1, ZW10

MVD, HMGCS1, DPAGT1, FDFT1, DOLK

6

$2.17 \quad 6.48 \mathrm{E}-04$ 
Table 4 DAVID Functional Annotation Clustering of SAM genes in VE vs. CON subcutaneous fat (Continued)

\begin{tabular}{|c|c|c|c|c|c|}
\hline GOTERM_BP_FAT & GO:0016090 prenol metabolic process & 3 & 1.09 & $2.46 \mathrm{E}-3$ & DPAGT1, FDFT1, DOLK \\
\hline GOTERM_BP_FAT & $\begin{array}{l}\text { GO:0016093 polyprenol metabolic } \\
\text { process }\end{array}$ & 3 & 1.09 & $2.46 \mathrm{E}-3$ & DPAGT1, FDFT1, DOLK \\
\hline \multicolumn{6}{|l|}{ Annotation Cluster 4} \\
\hline \multicolumn{6}{|l|}{ Enrichment Score: 1.72} \\
\hline GOTERM_BP_FAT & GO:0034660 ncRNA metabolic process & 13 & 4.71 & $3.28 \mathrm{E}-04$ & $\begin{array}{l}\text { GARS, EPRS, IARS, TRNT1, WDR55, NOLC1, METTL1, } \\
\text { ADAT2, NOP58, ALG11, NSUN2, FTSJ2, MARS }\end{array}$ \\
\hline GOTERM_BP_FAT & GO:0034470 ncRNA processing & 9 & 3.26 & $1.03 \mathrm{E}-2$ & $\begin{array}{l}\text { TRNT1, WDR55, NOLC1, METTL1, ADAT2, NOP58, } \\
\text { ALG11, FTSJ2, NSUN2 }\end{array}$ \\
\hline GOTERM_BP_FAT & GO:0042254 ribosome biogenesis & 6 & 2.17 & $4.59 \mathrm{E}-2$ & WDR55, TSR1, NOLC1, NOP58, ALG11, FTSJ2 \\
\hline \multicolumn{6}{|l|}{ Annotation Cluster 5} \\
\hline \multicolumn{6}{|l|}{ Enrichment Score: 1.68} \\
\hline GOTERM_BP_FAT & GO:0006399 tRNA metabolic process & 8 & 2.90 & $2.83 \mathrm{E}-3$ & $\begin{array}{l}\text { TRNT1, IARS, METTL1, ADAT2, GARS, EPRS, NSUN2, } \\
\text { MARS }\end{array}$ \\
\hline GOTERM_BP_FAT & GO:0043039 tRNA aminoacylation & 4 & 1.45 & $3.69 \mathrm{E}-2$ & IARS, GARS, EPRS, MARS \\
\hline GOTERM_BP_FAT & GO:0043038 amino acid activation & 4 & 1.45 & $3.69 \mathrm{E}-2$ & IARS, GARS, EPRS, MARS \\
\hline GOTERM_BP_FAT & $\begin{array}{l}\text { GO:0006418 tRNA aminoacylation for } \\
\text { protein translation }\end{array}$ & 4 & 1.45 & $3.69 \mathrm{E}-2$ & IARS, GARS, EPRS, MARS \\
\hline \multicolumn{6}{|l|}{ Annotation Cluster 6} \\
\hline \multicolumn{6}{|l|}{ Enrichment Score: 1.43} \\
\hline GOTERM_BP_FAT & GO:0016192 vesicle-mediated transport & 20 & 7.25 & $2.23 \mathrm{E}-3$ & $\begin{array}{l}\text { CAV2, RAB2B, LDLR, CNIH, VPS45, GARS, RER1, SNX4, } \\
\text { AP4S1, RAB1A, COPB2, AP1S1, TFRC, CDC42SE2, } \\
\text { ACTR1A, PIKFYVE, RAB22A, VPS4A, TRAPPC3, ZW10 }\end{array}$ \\
\hline GOTERM_BP_FAT & GO:0016044 membrane organization & 12 & 4.35 & 4.24E-2 & $\begin{array}{l}\text { CAV2, COPB2, AP1S1, DNM1L, LDLR, TFRC, CDC42SE2, } \\
\text { FXC1, RAB22A, PIKFYVE, SNX4, TIMM8A }\end{array}$ \\
\hline
\end{tabular}

Table 5 Real-time PCR confirmation of the microarray results

\begin{tabular}{lll}
\hline & Microarray & qPCR \\
Gene & VE vs CON & VE vs CON \\
\hline L.Thoracis & $-2.05^{* * *}$ & $-3.07^{* *}$ \\
CISH & $-1.22^{* * *}$ & -1.07 \\
ABCC4 & $-1.25^{* * *}$ & -1.42 \\
ACAT1 & $-1.17^{* *}$ & -1.03 \\
IGF1R & & \\
SUbCUTaneous fat & $2.66^{* * * *}$ & 2.25 \\
LDLR & $1.53^{* * * *}$ & 1.28 \\
METLL1 & $-2.78^{* * * *}$ & $-3.51^{* *}$ \\
SOD3 & $2.70^{* * * *}$ & 2.24 \\
SQLE & $1.76^{* * * *}$ & 1.73 \\
SREBF1 & $1.44^{* * * *}$ & 1.21 \\
HAX1 & $-1.53^{* * * *}$ & -2.24 \\
HMGB2 & $1.87^{* * * *}$ & 1.86 \\
HSPB8 & $-2.06^{* * * *}$ & $-2.54^{*}$ \\
IER3 & &
\end{tabular}

Gene expression changes in L. Thoracis muscle (CISH, ABCC4, ACAT1 and IGFIR) and subcutaneous fat (LDLR, SOD3, SQLE, SREBF1, HAX1, METLL1, HMGB2, HSPB8 and IER3) by the fold change (FC) obtained with microarray and qPCR data and their significance $\left(P<0.1^{*} ; P<0.05^{* *} ; P<0.01^{* * *} ; P<0.001^{* * *}\right)$ purchased at retail. The results related to the content of $\alpha$ tocopherol in the muscle and TBARS confirm what was planned in the methodology. Vitamin E has been successfully used to increase the muscle $\alpha$-tocopherol and to reduce lipid oxidation in beef and chicken meat [21]. In this study, as expected, there were significant differences between both diets in the $\alpha$-tocopherol content, lipid oxidation and MMb formation in the LT muscle, as previously found by Ripoll et al. [11]. Moreover, TBARS values were lower in VE lambs which showed that the lipid oxidation process was slower in animals fed this type of diet.

In the present study, we used microarray technology to study changes in gene expression profiles in LT muscle and SF in response to vitamin $\mathrm{E}$ supplementation in lambs. Our results, showed that vitamin E supplementation caused different responses in gene expression in LT muscle and SF, suggesting a specific response of tissue to vitamin $\mathrm{E}$ supplementation. In our study, we did not measure the concentration of VE in the SF, however the gene expression results might be related to the greater $\alpha$-tocopherol accumulation in adipose tissues than in skeletal muscles [22, 23].

It has been reported that $\alpha$-tocopherol can influence a number of biological functions by regulating cell signaling at both the mRNA and miRNA levels [7]. Indeed, our results showed that vitamin $\mathrm{E}$ supplementation affected the 
expression of 29 genes in the LT muscle. The results of functional analysis showed that genes related to the intracellular signaling cascade (CISH, IGF1R, DEF8, and $A K A P 7)$ and metabolic processes (ZNF79, MAFB, MYLK2, ACACB, ACAT1, CISH, IGF1R, PGLS, DUSP26, AKR7A2, $F B X L 4, A K A P 7$, and RSC1A1) were down-regulated. The enrichment scores were less than 1.3, likely because the number of significant genes in this contrast was low. The most down-regulated gene by vitamin E in LT was CISH (Cytokine Inducible SH2 containing protein). Chen et al. [24] reported that CISH activates protein kinase C (PKC) activity by G-protein coupled receptor protein, which is important for the activation of both the activator protein 1 (AP-1) and nuclear factor- $\kappa \mathrm{B}(\mathrm{NF}-\mathrm{\kappa} \mathrm{B})$ pathways. In a previous study Boscoboinik et al. [25], demonstrated that PKC is inhibited by $\alpha$-tocopherol. NF-kB proteins are a family of transcription factors and are of central importance in inflammation, immunity and apoptosis [26]. Evidence suggests a role for reactive oxidative intermediates (ROIs) as a common and critical intermediate for various NF- $\mathrm{NB}$-activating signals, based on inhibition of NF- $\mathrm{kB}$ activation by a variety of antioxidants [27, 28]. There is a bidirectional relationship between cytokines and oxidative stress. Exposure of myotubes to reactive oxygen species (ROS)-producing agents resulted in an increase in interleukin 6 (IL-6) release through the activation of the redox-sensitive transcription factor, NF- $\mathrm{kB}$ [28]. In this sense, $I L-6$ induces marked increases in expression of CISH, SOCS-1, SOCS-2, and SOCS-3 in tissues, which in turn result in inhibition of the signaling of wide range of cytokines [29]. Thus, CISH expression could be related to oxidative status in the muscle. In this sense, low levels of ROS and ROIs in muscle caused by $\alpha$ tocopherol could be associated with low expression of CISH. In this sense, lipid oxidation in the LT muscle and metmyoglobin formation were lower when lambs were supplemented with VE. In the same manner, RSC1A, which inhibits a dynamin and PKC-dependent exocytotic pathway of $S L C 5 A 1$ gene, was down-regulated in the VE group. Interestingly enough CISH and MYLK, also downregulated in the VE treatment, are involved in inflammation mediated by chemokine and cytokines signaling pathway, which could suggest another possible role for VE that of decreased inflammation.

In our study, alterations of the Ras homolog gene family, member A (RhoA) and actin cytoskeleton signaling were identified (IGF1R and MYLK2 genes). Both IGF1R and $M Y L K 2$ were down-regulated in VE treatment. Insulinlike growth hormone 1 (IGF-1) is a protein structurally similar to insulin, and it regulates tissue growth and development in several vertebrates [30]. As a main receptor of IGFs, IGF1R mediates the transduction of metabolic signals of cell proliferation, bone growth, and protein synthesis in the GH/IGF pathway [31]. In our study, IGF1R was down-regulated in VE treatment, and because of IGF1R polymorphisms have been associated to growth traits [32-36], we thought that this effect could be due to the higher ADG in CON animals. However, ADG values were included as a covariate in the statistical model used to validate expression differences by qPCR, thus avoiding estimation biases related to ADG. Therefore these results suggest that supplementation with VE causes down-regulation of IGF1R in LT muscle. Our findings are in agreement with Araujo et al. [37], who showed that VE supplementation reduces IGF1R expression by $17 \%$ in hyperthyroid of Wistar rats. In addition, Chuang et al. [38] also found that VE alone significantly and dose-dependently reduced the cell surface expression of IGFIR in HL-60 cells. Moreover, Holzenberger et al. [39] reported that $I g f 1 r^{+/-}$mice display greater resistance to oxidative stress.

In addition, vitamin $\mathrm{E}$ down-regulated two genes related to lipid metabolisms ( $A C A T 1$ and $A C A C B$ ) in the LT muscle. ACAT1 (acetyl-coenzyme A acetyltransferase 1) encodes a mitochondrial localized enzyme that catalyzes the reversible formation of acetoacetyl- CoA from two molecules of acetyl-CoA. ACAT1 is responsible for cholesterol homeostasis and maintain appropriate cholesterol availability in cell membranes, whereas $A C A C B$ is the key regulator of the fatty acid oxidation pathways [40]. It controls fatty acid oxidation by means of the ability of malonyl-CoA to inhibit carnitine-palmitoyl-CoA transferase I (CPT1B). As in our work, Shige et al. [41] showed that vitamin E reduced the uptake of modified low-density lipoprotein (LDL) and suppressed ACAT activity, resulting in less cholesterol esterification in macrophages. Interestingly enough $A B C C 4$, an ATP-binding cassette (ABC) transporter, $A K R 7 A 2$ which is involved in the detoxification of aldehydes and ketones, and finally RSC1A1 which transport carbohydrate across the plasma membrane, were all downregulated with VE treatment. In hepatocytes, $\mathrm{ABCC} 4$ was shown to be induced by oxidative stress through binding of the oxidative sensor nuclear factor E2-related factor 2 (Nrf2) to antioxidant-responsive element sequences in the promoter of $A B C C 4$ [42]. Our results showed for the first time that vitamin $\mathrm{E}$ down-regulates $A B C C 4$ expression. Because of significant differences in ADG between treatments, we validated the expression results of the CISH, $A B C C 4$, $A C A T 1$ and IGFR1 genes by qPCR, including in the statistical model ADG as a covariate. ADG was not significant, with a similar FC between the microarray and qPCR results $\left(r^{2}=0.99 ; P=0.008\right)$. Therefore, treatment was the main effect over gene expression.

In addition, we found that the transcription factors FHL3, ZNF777 and MAFB were down-regulated. Considering all together, our results showed that supplementation with VE increased the content of $\alpha$-tocopherol in the LT muscle and decreased metmyoglobin formation 
and lipid oxidation. We speculate that $\alpha$-tocopherol in the LT muscle causes a decrease in the catalytic activity of enzymes involved in cellular transport of fatty acids and carbohydrates, and fatty acid oxidation in the mitochondria. Decreased IGF1R expression might be related to the lower lipid oxidation levels in VE animals. We also found that IGFR1, ABCC4 ACAT1, CISH, ACACB, $M Y L K 2, Z N F 777$ and $M A F B$ were positively correlated with each other and with the diet, which suggest coexpression processes of these genes. We speculate that transcription factors ZNF777, MAFB and FHL3 could be important players in mediating the effects of VE in regulating the expression of these genes.

To establish whether IGFR1, ABCC4 and ACAT1, $\mathrm{CISH}$ are markers of meat oxidation or indirect markers of meat quality, further studies with greater numbers of animals are necessary.

A most dramatic effect of VE was observed on SF gene expression. ALG11, SRPBR, DDX47, SEC23ID and TTC37 were among the most important genes in discriminate fed treatments. These genes were up-regulated and positively correlated with each other and with the diet, which might suggest co-expression processes. Four of the up-regulated genes in the VE group were related to heat shock proteins (HSPs) or chaperonin activity (TTC37, DNAJC16, HSB8, AHSA1). Some HSPs are characterized by various specific functions such as anti-apoptotic or anti-inflammatory effects [43]. In our study, these genes were up-regulated and positively correlated, suggesting putative increased stress protection in VE lambs.

Surprisingly VE treatment showed general up-regulation of almost all significant genes, compared to CON treatment. Lipid biosynthetic processes were among the most enriched functional clusters with major biological significance and importance (PGAP3, EBP, CRLS1, MVD, CYP51A1, GNE, HMGCS1, DPAGT1, LSS, SIGMAR1, LPCAT3, FDFT1, DOLK, PIGM, SQLE, DHCR7, AGPAT9, LTA4H, PCYT2, and HSD17B7). Moreover, genes implicated in sterol, steroid and cholesterol biosynthesis processes (SREBF1, EBP, LDLR, MVD, CYP51A1, SQLE, DHCR7, INSIG1, HMGCS1, $L S S$, and FDFT1) were up-regulated in the SF of VE animals, compared to the CON group. It has been previously reported that tocopherols inhibited de novo cholesterol synthesis within enterocytes [44], and cause repression of genes (DHCR7 and HMGCS1) involved in the de novo synthesis of cholesterol in testes and adrenal glands [45]. The differences reported in previous studies and ours might be due to the different tissues analyzed. This supports even more our idea that there is a tissue specific response in response to VE supplementation. On the other hand, Wang et al. [46] found oxysterol-specific repressive effects in the CYP51A1 and FDFT1 genes, mediated via direct binding of the ligands to liver X receptor (LXR). Because of $\alpha$-tocopherol and other antioxidants can inhibit the oxidation of cholesterol [47], the VE group could have a lower quantity of oxysterols and then have inhibited the repression of cholesterol biosynthesis via LXR and oxysterols and upregulated the sterol, steroid and cholesterol biosynthesis processes. In this sense, several genes implicated in "the stress response" (SOD3, IER3, HMGB2, UACA, LUC7L3) were down-regulated in the VE group, compared to the CON group (Table 3 and Supplementary Table S1). Among them, SOD3 showed higher values of FC. This gene encodes a member of the superoxide dismutase (SOD) protein family that protects the extracellular space from the toxic effects of reactive oxygen intermediates by converting superoxide radicals into hydrogen peroxide and oxygen. This finding contradicts the results of previous studies, which suggested that grass-based treatments elevated the activity of antioxidants, such as glutathione and superoxide dismutase (SOD), compared to grainfeeding [1]. However, Kumar et al. [48] in the myocardium muscle and Strobel et al. [49] in the skeletal muscle of exercise-trained and sedentary rats, found that antioxidant supplements reduced the endogenous antioxidants SOD2 gene and protein and the glutathione peroxidase (GPx) gene and enzyme activity.

Another down-regulated gene in VE treatment was IER3. IER3-deficient NCM460 cells exhibited reduced reactive oxygen species levels, indicating increased antioxidative protection [50]. In our study, IER3 was down regulated in the VE group suggesting an increase in antioxidative protection. The role of $H M G B 1$ in recognizing aberrant or damaged DNA has been shown in multiple in vitro experiments. A recent study directly showed the accumulation of HMGB1 at sites of oxidative DNA damage in live cells, thus defining HMGB1 as a component of an early DNA damage response [51]. A similar function has been attributed to HMGB2 [52]. These authors hypothesized that HMGB1/2 proteins act as a sensor of DNA modification, and their interaction with chemically altered DNA changes the chromatin structure, thus inducing DNA damage responses.

Finally, a cluster related to tRNA metabolic processes was also significant (TRNT1, METTL1, ADAT2, NSUN2, IARS, GARS, EPRS and MARS). Aminoacyl-tRNA synthetases perform an essential function in protein synthesis by catalyzing the esterification of an amino acid to its cognate tRNA (IARS, GARS, EPRS and MARS). Considering all together, we speculate that in the SF, vitamin $\mathrm{E}$ exerts antiinflammatory effect and stress protection by increasing heat shock protein expression. Vitamin E reduces stress response probably as results of reduced reactive oxygen species levels. In addition animals supplemented with VE might have inhibited cholesterol oxidation in SF and enhanced sterol, steroid and cholesterol biosynthesis 
processes. And finally, we speculate that regulation of these gene expressions it could be mediated through tRNAs IARS, GARS, EPRS and MARS.

Regarding LT, we included ADG values as a covariate in the statistical model used to validate the expression differences by qPCR to avoid estimation biases. In this case, ADG was not significant, and a similar FC between microarray and qPCR results was found $\left(r^{2}=\right.$ $0.99 ; p<0.0001)$. Thus, the treatment was also the main effect over gene expression of SF.

Although we found differences in mRNA activity, it did not necessarily cause differences in metabolic processes. An increase in gene expression is not necessarily correlated with an increase in protein concentrations or enzyme activities. There are many processes between transcription and translation, including post-transcriptional, translational and protein degradation regulation, in controlling steady-state protein abundances [53]. Moreover, DNA microarray has been the technology of choice for transcriptome analysis in recent years. Nonetheless, array technology has several limitations which include: using microarray technology limits the researcher to detecting transcripts that correspond to existing genomic sequencing information; and background hybridization limits the accuracy of expression measurements, particularly for transcripts present in low abundance.

\section{Conclusion}

This study demonstrated the beneficial effects of vitamin E supplementation during fattening period in lambs by increasing $\alpha$-tocopherol content in the LT muscle and diminishing drastically the lipid oxidation of the meat. We observed a tissue-specific response to vitamin E supplementation. The gene expression profiles for $\mathrm{VE}$ and $\mathrm{CON}$ treatments were different in both LT and SF. Vitamin E supplementation had a dramatic effect on subcutaneous fat gene expression, showing a general up-regulation of genes, compared to CON treatment. Our study enabled us to identify novel genes (for example, IGF1R, ACAT1, $A B C C 4, A C A C B, S O D 3$, and IER3) and metabolic pathways related to vitamin $\mathrm{E}$ metabolism that might be implicated in meat quality. To the best of our knowledge, this study was the first to report the effect of vitamin E supplementation on gene expression in the LT muscle and SF of lambs. Future exploration of these genes is necessary for a better understanding of how vitamin $\mathrm{E}$ affects the oxidative processes that occur in meat products.

\section{Methods}

\section{Ethics statement}

All experimental procedures including the care of animals and euthanasia were performed in accordance with the guidelines of the European Union and with Spanish regulations for the use and care of animals in research and were approved by the Animal Welfare Committee of the Centro de Investigación y Tecnología agroalimentaria (CITA) (protocol number 2009-01_MJT). In all cases, euthanasia was performed by penetrating captive bolt followed by immediate exsanguination.

\section{Animals and sample collection}

Fourteen single reared male lambs of the Rasa Aragonesa breed were weaned at $48.28 \pm 0.85$ days of age. Seven lambs were fed a basal concentrate from weaning to slaughter (CON treatment, $24 \pm 2.62$ days). The remaining 7 lambs received for $4.71 \pm 2.62$ days the same basal concentrate as the CON group, and thereafter until slaughter, they received a similar concentrate with the same characteristics but enriched with $500 \mathrm{mg}$ dl- $\alpha$-tocopheryl acetate per $\mathrm{kg}$ of feed (VE treatment) for $33.28 \pm 1.07$ days. The ingredients and chemical composition of the feedstuffs are shown in Table 6. Prior to weaning, the CON and VE lambs suckled their mothers and had free access to their concentrates. The average concentrate intake of the CON and VE lambs during the experimental period was 24.3 and $25.1 \mathrm{~kg}$ per lamb, respectively. The experimental procedures, management of the animals and sample details for each group are described in detail in Ripoll et al. [11].

All of the lambs were slaughtered when they attained $22-24 \mathrm{~kg}$ of slaughter weight (SW), according to the specifications of Ternasco de Aragón Protected Geographical Indication (Regulation (EC) No. 1107/96), which stipulates that lambs must be less than 90 days old with a SW between 22 and $24 \mathrm{~kg}$. The lambs were slaughtered using

Table 6 Ingredients and chemical composition of the feedstuffs used in the experiment

\begin{tabular}{lll}
\hline Item & CON concentrate & VE concentrate \\
\hline Ingredients (\%) & & \\
Barley & 40.87 & 40.87 \\
Corn & 14.95 & 14.95 \\
Wheat & 20.08 & 20.08 \\
Soyabean meal & 19.78 & 19.78 \\
Salt & 0.39 & 0.39 \\
Carbonate & 1.64 & 1.64 \\
Mineral-vitamin mixture & 1.20 & 1.10 \\
Fat & 1 & 1 \\
Chemical composition & & \\
CP, g/kg DM & 175 & 175 \\
NDF, g/kg DM & 180 & 180 \\
ADF, g/kg DM & 45 & 45 \\
a-tocopherol, mg/kg DM & $27^{\mathrm{b}}$ & $480^{\mathrm{b}}$ \\
\hline
\end{tabular}

DM, dry matter; $C P$, crude protein; NDF, neutral detergent fibre; ADF, acid detergent fibre

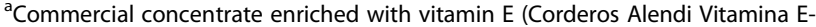
500, Ars Alendi S.A, Huesca, Spain). ${ }^{\text {bas }} \mathrm{mg}$ dl-a-tocopheryl acetate/kg DM 
EU laws in the same commercial abattoir, and the carcasses were hung by the Achilles tendon and chilled for $24 \mathrm{~h}$ at $4^{\circ}$ $\mathrm{C}$ in total darkness. The slaughter age, slaughter weight, and growth rate of the 2 management strategies are presented in Table 1.

Immediately after slaughter, a piece of LT muscle from the $12^{\text {th }}$ thoracic vertebra and a piece of SF between the atlas and axis cervical vertebrae were cut, frozen in liquid nitrogen and stored at-80 ${ }^{\circ} \mathrm{C}$ until RNA isolation.

\section{Analysis of a-tocopherol, intramuscular fat content, TBARS and metmyoglobin formation}

After chilling, a piece of the LT muscle between the $4^{\text {th }}$ and the $6^{\text {th }}$ lumbar vertebrae was vacuum-packed and kept at-20 ${ }^{\circ} \mathrm{C}$ in darkness until the $\alpha$-tocopherol analysis. The $\alpha$-tocopherol concentration was determined by liquid extraction as described in González-Calvo et al. [54]. A portion of the loin between the $7^{\text {th }}$ and the $13^{\text {th }}$ thoracic vertebrae was used to measure the LT muscle oxidative processes. The color (metmyoglobin content, $\mathrm{MMb}$ ) and lipid oxidation analysis (thiobarbituric acidreactive substance, TBARS) were quantified after 7 days of being maintained in darkness at $4{ }^{\circ} \mathrm{C}$. The LT muscle color and LT intramuscular fat oxidation were measured as described in González-Calvo et al. [54]. Briefly, the relative content of metmyoglobin $(\mathrm{MMb})$ was estimated by the $K / S_{572 / 525}$ ratio [55]. This ratio decreases when the $\mathrm{MMb}$ content increases. Intramuscular fat oxidation of the M. Longissimus thoracis was determined using the procedure reported by Pfalzgraf et al. [56]. The TBARS values are expressed as milligrams of malonaldehyde (MDA) kilogram ${ }^{-1}$ of muscle.

\section{RNA isolation and assessment of RNA integrity}

Total RNA was extracted from approximately $500 \mathrm{mg}$ of LT muscle or SF using RNeasy Tissue mini kits (QIAGEN, Madrid, Spain), following the manufacturer's protocol. Prior to microarray analysis, RNA integrity and quality were assessed by a RNA 6000 Nano LabChip on the Agilent 2100 Bioanalyzer (Agilent, Madrid, Spain) and were quantified using a nanophotometric spectrophotometer (Implen, Madrid, Spain). All RNA integrity number (RIN) values were greater than 8 .

\section{Microarray hybridization and data processing}

RNA samples ( $n=14,7$ samples from each treatment) were analyzed using Ovine Gene 1.1 ST Array Strip (Affymetrix, High Wycombe, UK). The Ovine gene 1.1 ST Array Strip allows for processing of four samples in parallel. This array contains a collection of 508538 probes that interrogate up to 26 unique sequences of each transcript (median probes/ transcript $=23$ ). These probes correspond to 22047 ovine genes. This study was part of a larger study in which we analyzed 84 samples corresponding to 3 treatments and 4 tissues (7 animals per treatment). In each strip, we hybridized the four tissues, selecting the animal tissue for each strip by random sampling. Microarray hybridization and scanning were performed at the Functional Genomics Core facility (Institute for Research in Biomedicine, IRB Barcelona, Spain), following the recommendations of the manufacturer. Scanned images (DAT files) were transformed into intensities (CEL files) by Affymetrix GeneChip Operating Software (GCOS). Overall array intensity was normalized between arrays to correct for systematic bias in the data and to remove the impact of non-biological influences on biological data. The imported data were analyzed at the gene-level, with exons summarized to genes, using the mean expression of all of the exons of a gene. Normalization was performed with the Robust Multi-Array Average (RMA) algorithm using quantile normalization, median polish probe summarization, and $\log 2$ probe transformation. The data sets supporting the results and discussed in this publication have been deposited in NCBI's Gene Expression Omnibus repository [57] and are accessible through GEO Series accession number GSE63774 (https://www.ncbi.nlm.nih.gov/geo/query/acc.cgi?acc= GSE63774? acc $=$ GSE63774).

\section{Validation of microarray data by qPCR}

One microgram of RNA from each sample were treated with DNAse (Invitrogen, Carlsbad, CA, USA), and single-stranded cDNA was synthesized using the SuperScript ${ }^{\oplus}$ III Reverse Transcriptase kit (Invitrogen, Carlsbad, CA, USA), following the manufacturer's recommendations. Specific exon-spanning primers for genes were generated and confirmed for specificity using BLAST (National Center for Biotechnology Information: http:// www.ncbi.nlm.nih.gov/BLAST/). Before performing the qPCR reactions,conventional PCR was performed for all of the genes to test the primers and to verify the amplified products. The PCR products were sequenced to confirm gene identity using an ABI Prism 3700 (Applied Biosystems) with standard protocols. Homology searches were performed with BLAST (National Center for Biotechnology Information: https://blast.ncbi.nlm.nih.gov/Blast.cgi) to confirm the identity of the amplified fragments. Quantitative reverse transcriptase polymerase chain reaction (qRT-PCR) was performed using SYBR Green Master Mix: SYBR Premix Ex Taq II (Tli RNase H Plus) and an ABI Prism 7500 platform (Applied Biosystem, Madrid, Spain). Standard curves for each gene were generated to calculate the amplification efficiency through 4-fold serial dilution of cDNA 
pooled from the LT muscle and SF. The efficiency of PCR amplification for each gene was calculated using the standard curve method $\left(E=10^{(-1 / \text { slope })}\right)$. Two "connector samples" were replicated in all of the plates to remove technical variation from this source of variability. The annealing temperatures, primer concentrations, and primer sequences for CISH, ABCC4, ACAT1, IGF1R, LDLR, SQLE, SREBF1, SOD3, HAX1, HMGB2, METTL1, HSPB8, and IER3 (genes of interest: GOIs) and the reference genes (GUSB and YWHAZ) are described in Table 7. These reference genes were chosen because in previous studies they have been shown to be the most stable in these tissues [5].
Statistical analysis

\section{Statistical analysis of performance, a-tocopherol and lipid} oxidation in the LT muscle

Statistical analysis was performed using a general lineal model (GLM). Treatment (CON and VE) was included as the fixed factor for weaning age (WA), slaughter age (SA), slaughter weight, intramuscular fat content (IMF) and average daily gain (ADG). For muscle $\alpha$-tocopherol, myoglobin and TBARS, the model also included intramuscular fat content and slaughter age as covariates. The results are expressed as least square means \pm the standard error (SE) values and the differences were tested at a level of significance of 0.05 with the $t$ statistic.

Table 7 Primers forward and reverse used in RT-PCR

\begin{tabular}{|c|c|c|c|c|c|c|c|}
\hline \multicolumn{8}{|c|}{$\overline{P C R}$ conditions $^{\mathrm{a}}$} \\
\hline Symbol & Gene & Primers forward and reverse & Amplicon bp & AT & $\mathrm{nM}$ & $E$ & $R^{2}$ \\
\hline \multirow[t]{2}{*}{$\mathrm{CISH}$} & \multirow[t]{2}{*}{ Cytokine inducible $\mathrm{SH}$-containing protein } & F:5'-agccaagaccttctcctacct-3' & \multirow[t]{2}{*}{96} & \multirow[t]{2}{*}{60} & \multirow[t]{2}{*}{$600 / 600$} & \multirow[t]{2}{*}{1.98} & \multirow[t]{2}{*}{0.99} \\
\hline & & R:5'-acgaggaagacagtgaagacg-3' & & & & & \\
\hline \multirow[t]{2}{*}{$A B C C 4$} & \multirow{2}{*}{$\begin{array}{l}\text { ATP-binding cassette, sub-family C (CFTR/MRP), } \\
\text { member } 4\end{array}$} & F: 5'-ccgtgagaaatttgcccactg-3' & \multirow[t]{2}{*}{128} & \multirow[t]{2}{*}{60} & \multirow[t]{2}{*}{$900 / 900$} & \multirow[t]{2}{*}{2.00} & \multirow[t]{2}{*}{0.99} \\
\hline & & R: 5'- gcaaaacatacggctcatcat-3' & & & & & \\
\hline \multirow[t]{2}{*}{ ACAT1 } & \multirow[t]{2}{*}{ A cetyl-Coenzyme A acetyltransferase 1} & F: 5'-gagctgtttctcttggacatcc-3' & \multirow[t]{2}{*}{118} & \multirow[t]{2}{*}{60} & \multirow[t]{2}{*}{$900 / 900$} & \multirow[t]{2}{*}{1.98} & \multirow[t]{2}{*}{0.99} \\
\hline & & R: 5'- cctcctcctccgttgcaaat-3' & & & & & \\
\hline \multirow[t]{2}{*}{ IGF1R } & \multirow[t]{2}{*}{ Insulin-like growth factor 1 receptor } & F: 5'-ccaaggcctgagaactccat-3' & \multirow[t]{2}{*}{122} & \multirow[t]{2}{*}{60} & \multirow[t]{2}{*}{$900 / 900$} & \multirow[t]{2}{*}{2.00} & \multirow[t]{2}{*}{0.98} \\
\hline & & R: $5^{\prime}-$ ctggacacacattcccgct-3' & & & & & \\
\hline$L D L R$ & Low density lipoprotein receptor & F:5'- gcatcaacttcgacaaccct $-3^{\prime}$ & 112 & 60 & $600 / 600$ & 2.00 & 0.98 \\
\hline & & $R: 5^{\prime}-$ tcctccaagctgaccatctg $-3^{\prime}$ & & & & & \\
\hline SQLE & Squalene epoxidase & F:5'-aatgtgttgcaggtccggtt-3' & 88 & 60 & $600 / 600$ & 1.98 & 0.98 \\
\hline & & R:5'- tagactgcgacgccaaagaa $-3^{\prime}$ & & & & & \\
\hline SREBF1 & Sterol regulatory element binding transcription & $\mathrm{F}: 5^{\prime}-$ ctgctatgcaggcagcac $-3^{\prime}$ & 99 & 60 & $200 / 200$ & 2.00 & 0.98 \\
\hline & & R:5'- ggttgatgggcagcttgt $-3^{\prime}$ & & & & & \\
\hline SOD3 & Superoxide dismutase 3, extracellular & F:5'-atccacgtgcaccagtttg-3' & 110 & 60 & $300 / 300$ & 2.00 & 0.98 \\
\hline & & R:5'-aagttgccaaagtcgecc-3' & & & & & \\
\hline HAX1 & HCLS1 associated protein X-1 & F:5'-taacccatcaagaggcaggc-3' & 115 & 60 & $600 / 600$ & 1.99 & 0.99 \\
\hline & & R:5'-gaccggaaccaacgtcctag-3' & & & & & \\
\hline HMGB2 & High-mobility group box 2 & F:5'-gccgtatgaacagaaagcagc-3' & 126 & 60 & $600 / 600$ & 1.94 & 0.99 \\
\hline & & R:5'-ttcttcttggagectgtcgg-3' & & & & & \\
\hline HSPB8 & Heat shock 22 kDa protein 8 & F:5'-agcaagaaggtggcatcgtt-3' & 126 & 60 & $400 / 400$ & 2.00 & 0.99 \\
\hline & & R:5'- cctggggagcttcgatgatc- $3^{\prime}$ & & & & & \\
\hline IER3 & Immediate early response 3 & F:5'-ttcaccttcgaccctctecc-3' & 130 & 60 & $400 / 400$ & 1.90 & 0.97 \\
\hline & & $R: 5^{\prime}-$ cctcgactggcagctgac- $3^{\prime}$ & & & & & \\
\hline METTL1 & Methyltransferase like 1 & F:5'-ggagctgcatgagtggatgt-3' & 104 & 60 & $600 / 600$ & 1.97 & 0.99 \\
\hline & & R:5'- tgcccagatgtcccacaatg-3' & & & & & \\
\hline GUSB & $\beta$-glucuronidase & F:5'-gcttcgagcagcagtggta-3' & 86 & 60 & $600 / 600$ & 1.99 & 0.99 \\
\hline & & R:5'-cacgtcgttgaagctggac-3' & & & & & \\
\hline YWHAZ & Tyrosine 3-monooxygenase/tryptophan & F:5'- tgtaggagcccgtaggtcatct-3' & 102 & 60 & $400 / 400$ & 1.99 & 0.98 \\
\hline & & R:5' - ttctctctgtattctcgagccatct-3 & & & & & \\
\hline
\end{tabular}




\section{Statistical analysis for the identification of differentially expressed genes by microarray analysis in $L T$ and $S F$} Normalized data were further analyzed using Babelomics (http://babelomics.bioinfo.cipf.es/) and MetaboAnalyst software [58]. Genes showing a statistically significant value of the Limma-test; $(P<0.01)$ were screened out as differentially expressed between the treatments. Significant genes were annotated based on similarity scores in blastn comparisons of Affymetrix Transcript cluster sequences against ovine sequences in GenBank. In addition, a second method, significance analysis of microarray (SAM), was used to identify and reconfirm differentially expressed genes in VE-CON contrasts. Furthermore, SAM was used to detect false positive significant genes from Limma-testing. SAM is a well-established statistical method for the identification of differentially expressed genes in microarray data analysis [58]. SAM is designed to address the FDR when running multiple tests on highdimensional microarray data. First, it assigns a significance score to each variable based on its relative change from the standard deviation of repeated measurements. Then, it chooses variables with scores greater than an adjustable threshold $\Delta$ and compares their relative differences from the distribution estimated by random permutations of the class labels. For each $\Delta$, a certain proportion of the variables in the permutation set will be found to be significant by chance. This number is used to calculate the FDR. Underestimation of the variability inflates the value of the statistic and can result in an increased number of false positives.

\section{Multivariate analysis of gene expression}

Multivariate analysis was performed using MetaboAnalyst, according to Xia et al. [58]. Principal component analysis (PCA), partial least squares discriminate analysis (PLSDA), and variable importance of projection (VIP) were used to cluster the samples based on the selected gene expression profiles. Principal component analysis was used to reduce the large set of variables (genes) into 2 principal components (PCA 1 and 2). PLS-DA was used to enhance the separation between the groups by summarizing the data into a few latent variables that maximized covariance between the response and the predictors. The corresponding loading plot was used to determine the genes most responsible for separation in the PLS-DA score plot. Based on the PLS-DA results, genes were plotted according to their importance in separating the dietary groups and each gene received a value called the variable importance in the projection. Variable importance in the projection values $>1$ suggests that the variable is significantly involved in the separation of groups [59]. Variables with the highest VIP values were the most powerful group of discriminators. We also investigated trends or patterns in gene expression changes.

\section{Hierarchical clustering analysis (HCA)}

Cluster analysis was performed using MetaboAnalyst. In (agglomerative) hierarchical cluster analysis, each sample begins as a separate cluster and the algorithm proceeds to combine them until all of the samples belong to one cluster. Two parameters must be considered when performing hierarchical clustering. The first is the similarity measure, and the other is the clustering algorithm. For distance measurements we used the Euclidian and Ward algorithm for clustering. The results are shown as a heatmap.

\section{Statistical analysis of gene expression validated by $q P C R$}

The corresponding mRNA levels were measured and analyzed by their quantification cycles (Cq). The statistical methods to analyze differences in the expression rate were performed following the method proposed by Steibel et al. [60]. The mixed model fitted was:

$$
\mathrm{y}_{\text {rigkm }} \mathrm{TG}_{\mathrm{gi}}+\mathrm{b}(\mathrm{IMF})_{\mathrm{m}}+\mathrm{b}(\mathrm{ADG}) \mathrm{m}+\mathrm{P}_{\mathrm{k}}+\mathrm{A}_{\mathrm{m}}+\mathrm{e}_{\text {rigkm }}
$$

where, $y_{\text {rigkm }}$ is the $C_{\mathrm{q}}$ value (transformed data taking into account $E<2)$ of the $\mathrm{g}^{\text {th }}$ gene (GOIs and housekeeping) from the $r^{\text {th }}$ well in the $k^{\text {th }}$ plate collected from the $\mathrm{m}^{\text {th }}$ animal subjected to the $\mathrm{i}^{\text {th }}$ treatment (CON, VE and ALF); $\mathrm{TG}_{\mathrm{gi}}$ is the fixed interaction among the $\mathrm{i}^{\text {th }}$ treatment and the $\mathrm{g}^{\text {th }}$ gene; $\mathrm{IMF}_{\mathrm{m}}$ (only used in $L$. Thoracis muscle tissue gene expression), and $\mathrm{ADG}_{\mathrm{m}}$ are the effects of intramuscular fat, and the average daily gain of the $\mathrm{m}^{\text {th }}$ animal included as covariates; $\mathrm{P}_{\mathrm{k}}$ is the fixed effect of the $\mathrm{k}^{\text {th }}$ plate; $\mathrm{A}_{\mathrm{m}}$ is the random effect of the $\mathrm{m}^{\text {th }}$ animal from which samples were collected $\left(\mathrm{A}_{\mathrm{m}} \sim\left(0, \sigma_{\mathrm{A}}^{2}\right)\right)$; and $\mathrm{e}_{\text {rigkm }}$ is the random residual. Gene specific residual variance (heterogeneous residual) was fitted to the gene by treatment effect $\left(e_{\text {rigkm }} \sim \mathrm{N}\left(0, \sigma_{\text {egi }}^{2}\right)\right.$.

To test differences $\left(\operatorname{diff}_{G O I}\right)$ in the expression rates of the target genes between treatments in terms of fold changes (FCs), the approach suggested by Steibel et al. [60] was used. The significance of the diff $_{G O I}$ estimates was determined with the $t$ statistic.

\section{Functional annotation analyses}

The Database for Annotation, Visualization and Integrated Discovery (DAVID) v6.7b [61], was used to determine the pathways and processes of major biological significance and importance through the Functional Annotation Cluster (FAC) tool based on the Gene Ontology (GO) annotation function. DAVID FAC analysis was performed with the gene lists obtained after SAM analysis. Medium stringency EASE score parameters were selected to indicate confident enrichment scores of functional significance and the importance of the given pathways and processes investigated. An enrichment score of 1.3 was employed as a threshold for cluster significance [61]. 


\section{Additional files}

Additional file 1: Table S1. The significant genes identified by SAM in VE vs. CON contrast. (DOCX $62 \mathrm{~kb}$ )

Additional file 2: Figure S1. Hierarchical clustering analysis in subcutaneous fat using 330 SAM genes. (DOCX 290 kb)

Additional file 3: Table S2. DAVID Functional Annotation Clustering of SAM genes in VE vs. CON muscle L. Thoracis. Only is shown the 2 most enrichment cluster. (DOCX 16 kb)

\section{Acknowledgments}

The authors wish to thank the staff of "CITA de Aragón" for its assistance in sample collection and analysis.

\section{Funding}

This study was funded by the Ministry of Education and Science of Spain and the European Union Regional Development funds (INIA-RTA 2012-0041 and RZP2013-0001) and the Research Group Funds of the Aragón Government (A49). L. González-Calvo was supported by a doctoral grant from INIA.

\section{Availability of data and materials}

The data sets supporting the results and discussed in this publication have been deposited in NCBI's Gene Expression Omnibus repository and are accessible through GEO Series accession number GSE63774.

\section{Authors' contributions}

LGC and PS performed the experiments. MJ, MS and JHC designed the research and obtained funding for this research. LGC, ED, MS, JMO and JHC wrote the paper. LGC, MS, ED, MJ, RMH, JMO and JHC analyzed the data. MJ provided the animals. JHC had primary responsibility for the final content. All of the authors contributed to the manuscript discussion. All of the authors read and approved the final manuscript.

\section{Competing interests}

The authors declare that they have no competing interests.

\section{Ethics approval and consent to participate}

All of the experimental procedures, including the care of animals and euthanasia, were performed in accordance with the guidelines of the European Union and with Spanish regulations for the use and care of animals in research and were approved by the Animal Welfare Committee of the Centro de Investigación y Tecnología Agroalimentaria (CITA) (protocol number 2009-01_MJT). In all cases, euthanasia was performed by penetrating captive bolt followed by immediate exsanguination.

\section{Author details \\ 'Unidad de Tecnología en Producción Animal, CITA, 59059 Zaragoza, Spain. 2University of Alberta, 116 St and 85 Ave, Edmonton, AB T6G 2R3, Canada. ${ }^{3}$ IMDEA-Alimentación, 28049 Madrid, Spain. ${ }^{4}$ Departamento de Mejora Genética Animal, INIA, 28040 Madrid, Spain. ${ }^{5}$ Jean Mayer-USDA Human Nutrition Research Center on Aging at Tufts University, Boston, MA, USA. ${ }^{6}$ ARAID, 50004 Zaragoza, Spain.}

Received: 15 April 2016 Accepted: 9 December 2016 Published online: 17 January 2017

\section{References}

1. Daley CA, Abbott A, Doyle PS, Nader GA, Larson S. A review of fatty acid profiles and antioxidant content in grass-fed and grain-fed beef. Nutr J. 2010;9:10.

2. Azzi A, Gysin R, Kempná P, Munteanu A, Negis Y, Villacorta L, Visarius T, Zingg J. Vitamin E mediates cell signaling and regulation of gene expression. Ann N Y Acad Sci. 2004;1031(1):86-95.

3. Rimbach G, Moehring J, Huebbe P, Lodge JK. Gene-Regulatory Activity of alpha-Tocopherol. Molecules. 2010;15(3):1746-61.

4. Nakamura YK, Omaye ST. Vitamin E-modulated gene expression associated with ROS generation. J Funct Foods. 2009;1(3):241-52.

5. González-Calvo L, Joy M, Alberti C, Ripoll G, Molino F, Serrano M, Calvo J. Effect of finishing period length with a-tocopherol supplementation on the expression of vitamin E-related genes in the muscle and subcutaneous fat of light lambs. Gene. 2014:552:225-33.

6. González-Calvo L, Joy M, Blanco M, Dervishi E, Molino F, Sarto P, Ripoll G, Serrano M, Calvo J. Effect of vitamin E supplementation or alfalfa grazing on fatty acid composition and expression of genes related to lipid metabolism in lambs. J Anim Sci. 2015:93:3044-54.

7. Gaedicke S, Zhang X, Schmelzer C, Lou Y, Doering F, Frank J, Rimbach G. Vitamin $\mathrm{E}$ dependent microRNA regulation in rat liver. FEBS Lett. 2008; 582(23):3542-6.

8. Tucker J, Townsend D. Alpha-tocopherol: roles in prevention and therapy of human disease. Biomed Pharmacother. 2005:59(7):380-7.

9. Jose C, Pethick D, Gardner G, Jacob R. The colour stability of aged lamb benefits from Vitamin E supplementation. Proceedings 54th international congress of meat science and technology. 2008;2008:1-3.

10. Jensen C, Lauridsen C, Bertelsen G. Dietary vitamin E: quality and storage stability of pork and poultry. Trends Food Sci Tech. 1998;9(2):62-72.

11. Ripoll G, González-Calvo L, Molino F, Calvo JH, Joy M. Effects of finishing period length with vitamin E supplementation and alfalfa grazing on carcass color and the evolution of meat color and the lipid oxidation of light lambs. Meat Sci. 2013;93(4):906-13.

12. Morrissey PA, Buckley DJ, Sheehy P, Monahan F. Vitamin E and meat quality. Proc Nutr Soc. 1994;53(02):289-95.

13. Barella L, Muller PY, Schlachter M, Hunziker W, Stocklin E, Spitzer V, Meier N, De Pascual-Teresa S, Minihane A-M, Rimbach G. Identification of hepatic molecular mechanisms of action of alpha-tocopherol using global gene expression profile analysis in rats. BBA Mol Basis Dis. 2004;1689(1):66-74.

14. Rota C, Rimbach G, Minihane A-M, Stoecklin E, Barella L. Dietary vitamin E modulates differential gene expression in the rat hippocampus: potential implications for its neuroprotective properties. Nutr Neurosci. 2005;8(1):21-9.

15. Nier B, Weinberg PD, Rimbach G, Stöcklin E, Barella L. Differential gene expression in skeletal muscle of rats with vitamin $E$ deficiency. IUBMB life. 2006:58(9):540-8.

16. Dervishi E, Joy M, Alvarez-Rodriguez J, Serrano M, Calvo J. The forage type (grazing versus hay pasture) fed to ewes and the lamb sex affect fatty acid profile and lipogenic gene expression in the longissimus muscle of suckling lambs. J Anim Sci. 2012:90(1):54-66.

17. Hebbachi AM, Knight BL, Wiggins D, Patel DD, Gibbons GF. Peroxisome Proliferator-activated Receptor alpha deficiency abolishes the response of lipogenic gene expression to re-feeding resoration of the normal response by activation of liver X receptor alpha. J Biol Chem. 2008;283(8):4866-76.

18. Lehnert S, Byrne K, Reverter A, Nattrass G, Greenwood P, Wang Y, Hudson $\mathrm{N}$, Harper G. Gene expression profiling of bovine skeletal muscle in response to and during recovery from chronic and severe undernutrition. J Anim Sci. 2006;84(12):3239-50.

19. Reverter A, Byrne K, Bruce H, Wang Y, Dalrymple B, Lehnert S. A mixture model-based cluster analysis of DNA microarray gene expression data on Brahman and Brahman composite steers fed high-, medium-, and lowquality diets. J Anim Sci. 2003;81(8):1900-10.

20. Culioli J, Berri C, Mourot J. Muscle foods: consumption, composition and quality. Sci Aliment. 2003;23(1):13-34

21. Bou R, Grimpa S, Baucells MD, Codony R, Guardiola F. Dose and duration effect of alpha-tocopheryl acetate supplementation on chicken meat fatty acid composition, tocopherol content, and oxidative status. J Agric Food Chem. 2006; 54(14):5020-6.

22. Lee JH, Waller JC, Melton SL, Saxton AM. Incorporation of alpha-tocopherol and linoleic acid in fresh lambs by feeding chemically treated dietary supplements containing dl-alpha-tocopheryl acetate and sunflower oil. J Agric Food Chem. 2006:54:568-73.

23. Liu Q, Lanari M, Schaefer D. A review of dietary vitamin e supplementation for improvement of beef quality. J Anim Sci. 1995:73:3131-40.

24. Chen S, Anderson PO, Li L, Sjögren H-O, Wang P, Li S-L. Functional association of cytokine-induced $\mathrm{SH} 2$ protein and protein kinase $\mathrm{C}$ in activated T cells. Int Imm. 2003;15(3):403-9.

25. Boscoboinik D, Szewczyk A, Hensey C, Azzi A. Inhibition of cell proliferation by alpha-tocopherol: Role of protein kinase C. J Biol Chem. 1991;266(10):6188-94.

26. Hayden MS, Ghosh S. Shared principles in NF-kappaB signaling. Cell. 2008; 132:344-62.

27. Schreck R, Albermann K, Baeuerle PA. Nuclear factor kappa B: an oxidative stress-responsive transcription factor of eukaryotic cells (a review). Free Rad Res Commun. 1992;17:221-37. 
28. Kosmidou I, Vassilakopoulos T, Xagorari A, Zakynthinos S, Papapetropoulos A, Roussos C. Production of interleukin- 6 by skeletal myotubes: Role of reactive oxygen species. Am J Respir Cell Mol Biol. 2002;26:587-93.

29. Starr R, Willson TA, Viney EM, Murray LJ, Rayner JR, Jenkins BJ, Gonda TJ, Alexander WS, Metcalf D, Nicola NA, Hilton DJ. A family of cytokine-inducible inhibitors of signalling. Nature. 1997;387:917-21.

30. Jones II, Clemmons DR. Insulin-Like Growth Factors and Their Binding Proteins: Biological Actions. Endocr Rev. 1995;16(1):3-34.

31. Delafontaine P, Song Y-H, Li Y. Expression, regulation, and function of IGF-1, IGF-1R, and IGF-1 binding proteins in blood vessels. Arterioscler Thromb Vasc Biol. 2004;24(3):435-44.

32. Lei M, Peng X, Zhou M, Luo C, Nie Q, Zhang X. Polymorphisms of the IGF1R gene and their genetic effects on chicken early growth and carcass traits. BMC Genet. 2008;9(1):70

33. Curi $\mathrm{R}$, De Oliveira H, Silveira A, Lopes C. Association between IGF-I, IGF-IR and GHRH gene polymorphisms and growth and carcass traits in beef cattle. Livest Prod Sci. 2005:94(3):159-67.

34. Zhang R, Li X. Association between IGF1R, m-calpain and UCP-3 gene polymorphisms and growth traits in nanyang cattle. Mol Biol Rep. 2011;38:2179-84

35. Szewczuk M, Zych S, Czerniawska-Piatkowska E, Wajcik J. Association between IGF1R/i16/Taql and IGF1/SnaBI polymorphisms and milk production traits in Polish Holstein-Friesian cows. Anim Sci Pap Rep. 2012;30(1):13-24.

36. El-Magd M, Abbas H, El-kattawy A, Mokhbatly A. Novel polymorphisms of the IGF1R gene and their association with average daily gain in Egyptian buffalo (Bubalus bubalis). Domest Anim Endocrinol. 2013;45(2):105-10.

37. Araujo AS, Enzveiler AT, Schenkel P, Fernandes TR, Ribeiro MF, Partata WA, Llesuy S, Belló-Klein A. Oxidative stress activates insulin-like growth factor I receptor protein expression, mediating cardiac hypertrophy induced by thyroxine Mol. Cell Biochem. 2007;303:89-95.

38. Chuang $\mathrm{CH}$, Huang $\mathrm{CS}$, Hu ML. Vitamin E and rutin synergistically inhibit expression of vascular endothelial growth factor through down-regulation of binding activity of activator protein-1 in human promyelocytic leukemia (HL-60) cells. Chem-Bioll Interact. 2010;183(3):434-41.

39. Holzenberger M, Dupont J, Ducos B, Leneuve P, Geloen A, Even PC, Cervera $P$, Le Bouc Y. IGF-1 receptor regulates lifespan and resistance to oxidative stress in mice. Nature. 2002;421(6919):182-7.

40. Abu-Elheiga L, Matzuk MM, Abo-Hashema KA, Wakil SJ. Continuous fatty acid oxidation and reduced fat storage in mice lacking acetyl-CoA carboxylase 2. Science. 2001;291(5513):2613-6.

41. Shige H, Ishikawa T, Suzukawa M, Nishiwaki M, Yamashita T, Nakajima K, Ito T, Higashi K, Ayaori M, Yonemura A, Nestel P, Nakamura H. Vitamin E reduces cholesterol esterification and uptake of acetylated low density lipoprotein in macrophages. Lipids. 1998;33(12):1169-75.

42. Maher JM, Dieter MZ, Aleksunes LM, Slitt AL, Guo G, Tanaka Y, Scheffer GL, Chan JY, Manautou JE, Chen Y. Oxidative and electrophilic stress induces multidrug resistance-associated protein transporters via the nuclear factor-2 related factor-2 transcriptional pathway. Hepatology. 2007;46(5):1597-610.

43. Vafiadaki E, Lam C, Zhao W, Arvanitis D, Sanoudou D, KontrogianniKonstantopoulos A, Kranias E. HAX-1: a mitochondrial anti-apoptotic protein with emerging roles in cardiac muscle. Heart. 2011;97(24):e8.

44. Landrier J-F, Gouranton E, Reboul E, Cardinault N, El Yazidi C, MalezetDesmoulins C, André M, Nowicki M, Souidi M, Borel P. Vitamin E decreases endogenous cholesterol synthesis and apo-Al-mediated cholesterol secretion in Caco-2 cells. J Nutr Biochem. 2010;21(12):1207-13.

45. Barella L, Rora C, Stöcklin E, Rimbach G. Alpha-Tocopherol Affects Androgen Metabolism in Male Rat. Ann N Y Acad Sci. 2004;1031(1):334-6.

46. Wang Y, Rogers PM, Su C, Varga G, Stayrook KR, Burris TP. Regulation of cholesterologenesis by the oxysterol receptor, LXRalpha. J Biol Chem. 2008;283(39):26332-9.

47. Csallany AS, Hee-Lee J, Shoeman DW. Protection of superoxide-induced cholesterol oxidation by antioxidants in protic conditions. Int J Food Sci Nut. 2002;53:403-9.

48. Kumar CT, Reddy VK, Prasad M, Thyagaraju K, Reddanna P. Dietary supplementation of vitamin $E$ protects heart tissue from exercise-induced oxidant stress. Mol Cell Biochem. 1992:111(1-2):109-15.

49. Strobel NA, Peake JM, Matsumoto A, Marsh SA, Coombes JS, Wadley GD Antioxidant supplementation reduces skeletal muscle mitochondrial biogenesis. Med Sci Sports Exerc. 2010;43(6):1017-24.

50. Stachel I, Geismann C, Aden K, Deisinger F, Rosenstiel P, Schreiber S, Sebens S, Arlt A, Schafer H. Modulation of nuclear factor E2-related factor-2 (Nrf2) activation by the stress response gene immediate early response-3 (IER3) in colonic epithelial cells. J Biol Chem. 2014;289(4):1917-29.

51. Prasad R, Liu Y, Deterding LJ, Poltoratsky VP, Kedar PS, Horton JK, Kanno S-I, Asagoshi K, Hou EW, Khodyreva SN. HMGB1 is a cofactor in mammalian base excision repair. Mol Cell. 2007;27(5):829-41.

52. Krynetskaia NF, Phadke MS, Jadhav SH, Krynetskiy EY. Chromatin-associated proteins HMGB1/2 and PDIA3 trigger cellular response to chemotherapyinduced DNA damage. Mol Cancer Ther. 2009;8(4):864-72.

53. Vogel C, Marcotte EM. Insights into the regulation of protein abundance from proteomic and transcriptomic analyses. Nat Rev Genet. 2012;13(4):227-32.

54. González-Calvo L, Ripoll G, Molino F, Calvo JH, Joy M. The relationship between muscle a-tocopherol concentration and meat oxidation in light lambs fed vitamin E supplements prior to slaughter. J Sci Food Agri. 2015;95:103-10.

55. Hunt M. Meat color measurements. Reciprocal Meat Conf Proc. 1980;33:41-6.

56. Pfalzgraf A, Frigg M, Steinhart H. Alpha-tocopherol contents and lipid oxidation in pork Muscle and adipose tissue during storage. J Agr Food Chem. 1995;43(5):1339-42.

57. Barrett T, Wilhite SE, Ledoux P, Evangelista C, Kim IF, Tomashevsky M, Marshall KA, Phillippy KH, Sherman PM, Holko M. NCBI GEO: archive for functional genomics data sets-update. Nucleic Acids Res. 2013;41(D1):D991-5.

58. Xia J, Psychogios N, Young N, Wishart DS. MetaboAnalyst: a web server for metabolomic data analysis and interpretation. Nucleic Acids Res. 2009;37 suppl 2:W652-60.

59. Szeto SS, Reinke SN, Sykes BD, Lemire BD. Mutations in the Saccharomyces cerevisiae succinate dehydrogenase result in distinct metabolic phenotypes revealed through $1 \mathrm{H}$ NMR-based metabolic footprinting. J Proteome Res. 2010;9(12):6729-39.

60. Steibel JP, Poletto R, Coussens PM, Rosa GJM. A powerful and flexible linear mixed model framework for the analysis of relative quantification RT-PCR data. Genomics. 2009;94(2):146-52.

61. Huang DW, Sherman BT, Lempicki RA. Systematic and integrative analysis of large gene lists using DAVID bioinformatics resources. Nat Protoc. 2008:4(1):44-57.

\section{Submit your next manuscript to BioMed Central and we will help you at every step:}

- We accept pre-submission inquiries

- Our selector tool helps you to find the most relevant journal

- We provide round the clock customer support

- Convenient online submission

- Thorough peer review

- Inclusion in PubMed and all major indexing services

- Maximum visibility for your research

Submit your manuscript at www.biomedcentral.com/submit
Biomed Central 